\title{
Modelling of sediment transport and morphological evolution under the combined action of waves and currents
}

\author{
Guilherme Franz $^{1}$, Matthias T. Delpey ${ }^{2}$, David Brito ${ }^{3}$, Lígia Pinto ${ }^{1}$, Paulo Leitão ${ }^{4}$, and Ramiro Neves ${ }^{1}$ \\ ${ }^{1}$ MARETEC, Instituto Superior Técnico, Universidade de Lisboa, Av. Rovisco Pais, 1049-001, Lisboa, Portugal \\ ${ }^{2}$ Centre Rivages Pro Tech, SUEZ, 2 allée Théodore Monod, Bidart, France \\ ${ }^{3}$ ACTION MODULERS, Estrada Principal, no. 29, Paz, 2640-583 Mafra, Portugal \\ ${ }^{4}$ HIDROMOD, Rua Rui Teles Palhinha, no. 4, Leião, 2740-278 Porto Salvo, Portugal \\ Correspondence to: Guilherme Franz (guilherme.franz@tecnico.ulisboa.pt)
}

Received: 24 February 2017 - Discussion started: 21 March 2017

Revised: 17 July 2017 - Accepted: 25 July 2017 - Published: 7 September 2017

\begin{abstract}
Coastal defence structures are often constructed to prevent beach erosion. However, poorly designed structures may cause serious erosion problems in the downdrift direction. Morphological models are useful tools to predict such impacts and assess the efficiency of defence structures for different scenarios. Nevertheless, morphological modelling is still a topic under intense research effort. The processes simulated by a morphological model depend on model complexity. For instance, undertow currents are neglected in coastal area models $(2 \mathrm{DH})$, which is a limitation for simulating the evolution of beach profiles for long periods. Model limitations are generally overcome by predefining invariant equilibrium profiles that are allowed to shift offshore or onshore. A more flexible approach is described in this paper, which can be generalised to 3-D models. The present work is based on the coupling of the MOHID modelling system and the SWAN wave model. The impacts of different designs of detached breakwaters and groynes were simulated in a schematic beach configuration following a $2 \mathrm{DH}$ approach. The results of bathymetry evolution are in agreement with the patterns found in the literature for several existing structures. The model was also tested in a 3-D test case to simulate the formation of sandbars by undertow currents. The findings of this work confirmed the applicability of the MOHID modelling system to study sediment transport and morphological changes in coastal zones under the combined action of waves and currents. The same modelling methodology was applied to a coastal zone (Costa da Caparica) located at the mouth of a mesotidal estuary (Tagus Estuary, Portugal) to evaluate the hydrodynamics and sediment transport both in calm wa-
\end{abstract}

ter conditions and during events of highly energetic waves. The MOHID code is available in the GitHub repository.

\section{Introduction}

The morphological features of the coastal zone depend on the sediment characteristics and the combined action of waves and currents. Wind waves are the main energy source for most beaches. Particularly in the surf zone, waves may induce considerable changes in mean sea level and strong currents (Longuet-Higgins, 1970a, b, 1983). The pattern of surf zone currents varies with the angle of waves approaching the shore as well as with bathymetric heterogeneities, leading to longshore and rip currents. Sediment is usually carried shoreward during low wave conditions, mainly due to the asymmetry of waves in shallow waters (Myrhaug et al., 2004). The sediment accumulated during these periods may be eroded very rapidly under high wave conditions during a major storm. Following these energetic events, the bottom profile may recover its initial shape only if the longshore transport of sediment during the storm is low. Different structures such as breakwaters and groynes can prevent the alongshore movement of sediment (e.g. Dally and Pope, 1986). Consequently, serious erosion problems in the downdrift direction may arise from the construction of these structures. Morphological models are useful tools to assess the impact of protection structures, enabling us to consider different wave conditions and structure designs. 
The complexity of morphological models ranges from coastal profile models to 2- or 3-D models. Actually, morphological models are usually a set of different models or modules, depending on the chosen approach. Here the focus is on the coupling of a spectral wave model with a phaseaveraged hydrodynamic and sediment transport model. Spectral wave models offer a representation of the physical processes related to the generation, propagation, and dissipation of waves (e.g. Booij et al., 1999). The wave-induced forces computed by a wave model can be provided to a hydrodynamic model in order to simulate wave-related phenomena, such as wave set-up, wave-induced currents, and mixing. On the other hand, the hydrodynamic model can return water levels and currents to the wave model (e.g. Warner et al., 2008). Additional processes can be considered in the hydrodynamic model, such as wind action, tidal motion, and river discharges. The transport of suspended sediment may be simulated by an advection/diffusion model. The mechanism of erosion/deposition of sediments is controlled by the bed shear stress induced by currents and waves. The bathymetry evolution resulting from the total sediment transport (suspended load and bed load) affects the patterns of currents and waves. Due to the interdependence of the physical processes involved in sediment dynamics, all of these models must be coupled.

The hydrodynamics inside the surf zone is influenced by important 3-D effects. Due to the absence of 3-D processes (e.g. undertow), coastal area models (2DH) fail to reproduce a consistent evolution of beach profiles for long periods. This shortcoming can be overcome by predefining invariant equilibrium profiles. In this case, the equilibrium profile only shifts offshore or onshore depending on the overall sediment balance along the profile, similarly to a coastal profile model (e.g. Kriebel and Dean, 1985; Kristensen et al., 2013). As the sediment transport in the swash zone is usually neglected in large-scale 2DH models, this approach also has the advantage of updating the shoreline position. However, limitations arise when a structure is present in the surf zone. Moreover, the processes responsible for sandbar evolution are not considered. Attempts to simulate sandbar dynamics have been performed generally with cross-shore 2-D (2DV) and quasi3-D models (e.g. Drønen and Deigaard, 2007; Ruessink et al., 2007). Nevertheless, the proper reproduction of sandbar migration is still an active topic of research (e.g. Dubarbier et al., 2015). Inaccuracies in the cross-shore sediment transport may degrade the coastal profile, which is a restriction for the simulation of long-term morphological evolution.

In this work, we test a more flexible approach to overcoming the 2DH model limitations in order to simulate morphological evolution for long periods. Instead of fixing an equilibrium profile to update the bathymetry and shoreline position, we defined a maximum slope that when surpassed generates sediment transport in the downslope direction. Thus, rather than extrapolating erosion or deposition fluxes over the entire profile, only individual grid cells are affected. This approach may be more appropriate in order to consider the effect of non-uniform grain-size distributions on the overall sediment transport, through morphological models that account for multiple sediment fractions. Grain-size sorting is generally observed along the cross-shore beach profile, as well as in the longshore beach direction (Komar, 1998). Furthermore, the method can be generalised to 3-D models for a better representation of sandbar slopes and to update the shoreline position.

This paper is divided into five sections. A brief description of the effect of waves in the nearshore hydrodynamics and sediment transport is given in Sect. 2. The numerical modelling approach is presented in Sect. 3. The methodology was verified for different test cases (Sect. 4). Firstly, the morphological evolution of a schematic beach was evaluated for different designs of coastal defence structures (detached breakwaters and groynes) following a 2DH model configuration. The model was applied later in a 3-D configuration for the same schematic beach to verify the development of sandbars. Finally, the numerical modelling methodology was applied to assess the hydrodynamics and sediment transport under extreme wave conditions in a coastal zone (Costa da Caparica) located at the mouth of a mesotidal estuary (Tagus Estuary, Portugal). The main conclusions found from these test cases are discussed in Sect. 5.

\section{Background}

The effect of breaking waves on the mean sea level (wave set-up) has been known since the laboratory measurements performed by Saville (1961), confirmed further by Bowen et al. (1968). This tilt of the mean sea level is explained by the horizontal flux of momentum carried by waves or, equivalently, by the radiation stress, a vertically integrated momentum flux whose gradient balances the wave set-up (LonguetHiggins and Stewart 1962, 1964). In the surf zone, wave heights and orbital velocities decrease towards the shore due to wave breaking. As a consequence, the radiation stress also decreases, resulting in a force directed towards the shore. This force is balanced by a hydrostatic pressure gradient that increases the mean sea level onshore.

Breaking waves can also drive strong currents in the surf zone, which are important for sediment transport and morphological evolution in the coastal zone. The horizontal mass transport associated with waves, or Stokes drift, is oriented shoreward and vertically sheared, being more intense at the surface (e.g. Ardhuin et al., 2008). As a result, mass conservation in the nearshore is satisfied by a seaward transport in the lower part of the water column, called undertow, which has an important role in sandbar formation. The undertow is strongest in steep beaches and may be insignificant for moderate beach slopes, where circulation tends to break up into rip currents (Longuet-Higgins, 1983). Also, obliquely breaking waves generate longshore currents (Longuet-Higgins, 
1970a, b) and, consequently, longshore sediment transport. Although nearshore sediment dynamics are dominated by wave action, tidal motion can also play an important role, alternately moving the breaker zone and shoreline position shoreward and seaward, which may prevent the development of longshore bars in the surf zone (e.g. Levoy et al., 2000).

\section{Numerical model}

The present work is based on the coupling of the MOHID modelling system (Leitão, 2003; Leitão et al., 2008) and the SWAN wave model (Booij et al., 1999). The MOHID code organisation follows an object oriented strategy that permits the integration of different scales and processes. Herein, the focus is given to the hydrodynamics and sediment transport in the nearshore area. Thus, we considered the processes related to the hydrodynamics, turbulence, advection/diffusion of suspended sediment, erosion/deposition of sediments, bed load sediment transport, and morphological evolution. A brief description of the most important aspects of the hydrodynamic model for this work is presented in this section, followed by the main novelties implemented in the MOHID code: a new method to calculate the bed load transport under the combined effect of currents and waves; and a bed slope correction considered to overcome the 2DH model limitations and to update the shoreline. This work represents an extension of the development of the morphological model previously described in Franz et al. (2017).

The SWAN wave model represents the processes of wave generation, propagation, refraction, shoaling, non-linear (quadruplet and triad) wave-wave interactions, and dissipation (whitecapping, bottom friction, and depth-induced breaking). More information can be found in the documentation of the SWAN wave model (http://swanmodel. sourceforge.net/). Both MOHID and SWAN can be run with multiple processors using shared (OpenMP) or distributed (OpenMPI) memory architectures. In this work, we implemented MPI directives in the MOHID module responsible for the calculations of bed load transport and morphological evolution (sediment module), which can consider multiple sediment classes. In addition to speeding up morphological changes by an acceleration factor, this new development reduces the computational time required for modelling bed evolution over long time periods.

\subsection{Hydrodynamic model}

The MOHID hydrodynamic module solves the NavierStokes equations, considering the incompressibility, hydrostatic, Boussinesq, and Reynolds approximations (Martins, 2000; Leitão, 2003):

$$
\begin{aligned}
\frac{\partial}{\partial t} \int_{V} \boldsymbol{v}_{\mathrm{H}} \mathrm{d} V & =-\oint_{A} \boldsymbol{v}_{\mathrm{H}}(\boldsymbol{v} \cdot \boldsymbol{n}) \mathrm{d} A+\oint_{A} v_{\mathrm{T}}\left(\nabla\left(\boldsymbol{v}_{\mathrm{H}}\right) . \boldsymbol{n}\right) \mathrm{d} A \\
& -\frac{1}{\rho} \oint_{A} p \cdot \boldsymbol{n}_{\mathrm{H}} \mathrm{d} A+\int_{V} 2 \boldsymbol{\Omega} \times \boldsymbol{v}_{\mathrm{H}} \mathrm{d} V+\boldsymbol{F},
\end{aligned}
$$

where $V$ represents the control volume, $\boldsymbol{v}_{\mathrm{H}}=(u, v)$ the horizontal velocity vector, $\boldsymbol{v}=(u, v, w)$ the velocity vector, $\boldsymbol{n}$ the normal vector to the bounding surface $(A), \boldsymbol{n}_{\mathrm{H}}$ the normal vector related to the horizontal plane, $v_{\mathrm{T}}$ the turbulent viscosity, $\rho$ the water density, $p=g \int_{z}^{\eta} \rho \mathrm{d} z+p_{\text {atm }}$ the water pressure, $g$ the gravitational acceleration, $p_{\text {atm }}$ the atmospheric pressure, $\eta$ the water level, $\boldsymbol{\Omega}$ the earth rotation vector, and $\boldsymbol{F}$ the external forces, which include the waveinduced force (gradient of the radiation stress) computed by the wave model. The wave-induced force was considered in the MOHID hydrodynamic module in previous studies to compute the effects of waves on sea level (Malhadas et al., 2009), water renewal in a coastal lagoon (Malhadas et al., 2010), and coastal water dispersion in an estuarine bay (Delpey et al., 2014).

The spatial discretisation is performed by following the finite-volume method. The water level and vertical velocity are computed through the continuity equation integrated over the entire water column or applied to each control volume, respectively. The equations are solved through the alternating direction implicit (ADI) method in an Arakawa C-grid structure. A generic vertical discretisation allows implementation of different types of vertical coordinates (e.g. Sigma or Cartesian) (Martins, 2001). The turbulent viscosity is computed differently for the horizontal and vertical directions. The horizontal turbulent viscosity is defined as a constant value, based on the grid resolution and a reference velocity, or as a function of horizontal velocity gradients, based on Smagorinsky (1963). The vertical turbulent viscosity is computed by the Global Ocean Turbulence Model (GOTM), which is coupled to MOHID and consists of a set of turbulence-closure models (Buchard et al., 1999; Villarreal et al., 2005). Effects of wave breaking on vertical turbulence can be taken into account through surface boundary conditions (Delpey et al., 2014)

To solve the Navier-Stokes and continuity equation, appropriate boundary conditions are required for the lateral (e.g. land and open sea), surface, and bottom boundaries. MOHID has the option of a great variety of open boundary conditions of several types: Dirichlet, Neumann, radiation, cyclic, relaxation (or nudging), etc. Some boundary conditions can be combinations of the types enumerated, e.g. a combination of radiation with nudging (Blumberg and Kantha, 1985). Open boundary conditions (OBCs) can be imposed by prescribing the values of a specific variable (Dirichlet boundary condition). This condition is commonly applied in coastal models to impose tidal levels when the correspondent barotropic velocities are not available. On the other 
hand, following a Neumann boundary condition, the gradient of a specific variable is imposed instead of a prescribed value. Assuming a null gradient condition, the value of a variable at a boundary point is equal to the value at an adjacent interior point. When the shoreline location and bathymetry are uniform, e.g. in schematic cases, cyclic boundary conditions can be applied.

A relaxation scheme can be applied as an OBC by assuming a decay time that increases gradually from the boundary to infinite after a defined number of cells (see Martinsen and Engedahl, 1987; Engedahl, 1995):

$P^{t+\Delta t}=P^{*}+\left(P^{\mathrm{ext}}-P^{*}\right) \frac{\Delta t}{T_{d}}$,

where $P$ is a generic property, $P^{*}$ is the property value calculated by the model, $P^{\text {ext }}$ is the reference value of the property, $\Delta t$ is the model time step, and $T_{d}$ is the relaxation timescale.

Radiation methods can also be used to impose the OBCs, which allow the propagation of internal disturbances on water levels through the open boundaries. These disturbances can be caused, for example, by the wave forces. MOHID has two types of radiation conditions (Leitão, 2003), based on Blumberg and Kantha (1985), Eq. (3), and Flather (1976), Eq. (4):

$$
\frac{\partial \eta}{\partial t}+\left(\boldsymbol{C}_{\mathrm{E} \cdot \boldsymbol{n})} \Delta \eta=\frac{1}{T_{d}}\left(\eta_{\mathrm{ext}}-\eta\right),\right.
$$$$
q-q_{\mathrm{ext}}=\left(\eta_{\mathrm{ext}}-\eta\right)\left(\boldsymbol{C}_{\mathrm{E}} \cdot \boldsymbol{n}\right)
$$

where $\eta$ and $q$ are the water level and specific flow, respectively; $\eta_{\text {ext }}$ and $q_{\text {ext }}$ are the imposed values of $\eta$ and $q$ at open boundary points; $\boldsymbol{C}_{\mathrm{E}}$ is the celerity of internal water level disturbances or the celerity of external waves $\left(C_{\mathrm{E}}=\sqrt{g h}\right)$. When $T_{d}$ is approximated to infinity in the Eq. (3), the OBC becomes totally passive, which means that the water levels at the boundary points are computed only from the internal water levels. An approximated null relaxation timescale means that the water level is imposed as $\eta_{\text {ext }}$. The Flather radiation condition is mostly used in nested model domains, when velocities and water levels are known at the open boundaries. Many of the OBCs used by MOHID considered the concept of an external (or reference) solution. These solutions can be provided via input file or via a one-way nesting of a chain of models. This last process is used to downscale from largescale domains to local ones (e.g. Franz et al., 2016).

In the case of land points, the closed boundary condition is imposed as null fluxes of mass and momentum in the perpendicular direction. However, for the parallel direction two boundary conditions can be used in MOHID: no-slip and free-slip (Leitão, 2003). In the no-slip condition, the normal and parallel velocities in the land boundary are assumed to be equal to zero. This generates a persistent gradient in the velocity components parallel to the land boundary and, consequently, a persistent sink associated with the horizontal turbulent diffusion of momentum. The covering and uncovering of boundary cells can be represented in MOHID by a wetting/drying scheme (Martins et al., 2001).

At the surface, fluxes of momentum from wind action and wave breaking can be considered (Delpey et al., 2014). At the bottom, the method proposed by Soulsby and Clarke (2005) to compute the bed shear stress was implemented in this work, consisting of a steady component due to currents together with an oscillatory component due to waves. In a laminar flow, the combined bed shear stress is a simple linear addition of the laminar current-alone and wave-alone shear stresses. However, in turbulent flows this addition is nonlinear and the mean and oscillatory components of the stress are enhanced beyond the values of the laminar case. The mean bed shear stress is used for determining the friction acting on the current, whereas the maximum shear stress is used to determine the threshold of sediment motion. The turbulence generated by the skin friction acts directly on bottom sediment grains (Einstein, 1950), contrarily to that related to bed forms. Thus, the threshold of sediment motion depends on the grain-related bed shear stress.

\subsection{Sediment transport}

The transport of sand is divided into suspended and bed load, in which the sand particles are in frequent contact with the bed. The suspended sediment transport is computed by resolving the advection/diffusion equation. This approach is more realistic than considering empirical equations based on the instantaneous bed shear stresses, as the suspended load is not in equilibrium with the instantaneous bed shear stresses in unsteady flows. The net upward flux of suspended sand depends on the equilibrium concentration near the bottom, estimated by empirical equations available in the literature, extrapolated following the Rouse profile to the middle of the near-bed layer, which in 2DH mode means the middle of the water column. The adopted methodology was described previously in Franz et al. (2017), converging for different numbers of vertical layers.

The bed load transport under the combined effect of currents and waves is computed following the semi-empirical formulation of Soulsby and Damgaard (2005). The formulation was derived for current plus sinusoidal and asymmetrical waves, as well as asymmetrical waves alone. Amoudry and Liu (2010) obtained a generally good agreement comparing the results of Soulsby and Damgaard (2005) formulations with a sheet flow model, concluding that it can be implemented in both intrawave and wave-averaged models in order to study sediment transport. The parallel $\Phi_{\|}$and normal $\Phi_{\perp}$ components of the non-dimensional bed load transport vector in relation to the current direction are 


$$
\begin{aligned}
& \Phi_{\|}=\max \left(\Phi_{\| 1}, \Phi_{\| 2}\right) ; \text { if } \theta_{\max }>\theta_{\mathrm{cr}}, \\
& \Phi_{\| 1}=k_{\Phi 1} \theta_{\mathrm{m}}^{k_{\Phi 2}}\left(\theta_{\mathrm{m}}-\theta_{\mathrm{cr}}\right)^{k_{\Phi 3}}, \\
& \Phi_{\| 2}=k_{\Phi 1}(0.9534+0.1904 \cos 2 \varnothing) \theta_{\mathrm{w}}^{1 / 2} \theta_{\mathrm{m}} \\
& \quad+k_{\Phi 1}\left(0.229 \gamma_{\mathrm{w}} \theta_{\mathrm{w}}^{3 / 2} \cos \varnothing\right),
\end{aligned}
$$

$$
\begin{aligned}
& \Phi_{\perp}=k_{\Phi 1} \frac{\left(0.1907 \theta_{\mathrm{w}}^{2}\right)}{\theta_{\mathrm{w}}^{3 / 2}+(3 / 2) \theta_{\mathrm{m}}^{3 / 2}}\left(\theta_{\mathrm{m}} \sin 2 \varnothing+1.2 \gamma_{\mathrm{w}} \theta_{\mathrm{w}} \sin \varnothing\right) ; \\
& \quad \text { if } \theta_{\max }>\theta_{\mathrm{cr}},
\end{aligned}
$$

where $\theta_{\mathrm{m}}$ and $\theta_{\mathrm{w}}$ are the time-mean and oscillatory part of the bed shear stress (non-dimensional), respectively; $k_{\Phi 1}, k_{\Phi 2}$, and $k_{\Phi 3}$ are calibration coefficients that allow one to represent different equations for the bed load transport found in the literature (e.g. Amoudry and Souza, 2011); $\varnothing$ is the angle between the wave propagation and current direction; $\gamma_{\mathrm{w}}$ is a factor that represents the wave's asymmetry; $\theta_{\mathrm{cr}}$ is the critical non-dimensional bed shear stress, which depends on sediment diameter and bed-material gradation. The bed load transport is null ( $\left.\Phi_{\|}=\Phi_{\perp}=0\right)$ if $\theta_{\text {cr }}$ is greater than or equal to the maximum non-dimensional bed shear stress $\left(\theta_{\max }\right)$ :

$$
\begin{aligned}
& \theta_{\max }=\max \left(\theta_{\max 1}, \theta_{\max 2}\right), \\
& \theta_{\max 1}=\left(\left(\theta_{\mathrm{m}}+\theta_{\mathrm{w}}\left(1+\gamma_{\mathrm{w}}\right) \cos \varnothing\right)^{2}\right. \\
& \left.\quad+\left(\theta_{\mathrm{w}}\left(1+\gamma_{\mathrm{w}}\right) \sin \varnothing\right)^{2}\right)^{1 / 2}, \\
& \theta_{\max 2}=\left(\left(\theta_{\mathrm{m}}+\theta_{\mathrm{w}}\left(1-\gamma_{\mathrm{w}}\right) \cos (\varnothing+\pi)\right)^{2}\right. \\
& \left.\quad+\left(\theta_{\mathrm{w}}\left(1-\gamma_{\mathrm{w}}\right) \sin (\varnothing+\pi)\right)^{2}\right)^{1 / 2},
\end{aligned}
$$

The bed load transport vector, $\boldsymbol{\Phi}=\left(\Phi_{\|}, \Phi_{\perp}\right)$, is enhanced in the presence of waves. Regarding the symmetrical case $\left(\gamma_{\mathrm{w}}=0\right)$, the effect of the wave's asymmetry results in an additional increase in the normal component $\left(\Phi_{\perp}\right)$, whereas the parallel component $\left(\Phi_{\|}\right)$can be increased or reduced, depending on the angle $(\varnothing)$ between the wave propagation and current direction. The asymmetry factor $\left(\gamma_{\mathrm{w}}=\theta_{\mathrm{w}, 2} / \theta_{\mathrm{w}, 1}\right)$ is defined as the ratio between the bed shear stress due to the wave's second harmonic $\left(\theta_{\mathrm{w}, 2}\right)$ and basic harmonic $\left(\theta_{\mathrm{w}, 1}\right)$, set to a maximum value of 0.2 (Soulsby and Damgaard, 2005). Considering the quadratic friction law to determine the magnitude of the wave's bed shear stress, the asymmetry factor is computed as

$\gamma_{\mathrm{w}}=\left(\frac{U_{\mathrm{w}, 2}}{U_{\mathrm{w}, 1}}\right)^{2}=\left(\frac{3}{4} \frac{\pi H_{\mathrm{w}}}{L_{\mathrm{w}} \sinh ^{3}\left(k_{\mathrm{w}} h\right)}\right)^{2}$,

where $U_{\mathrm{w}, 2}$ and $U_{\mathrm{w}, 1}$ are the amplitude of near-bed waveorbital velocity for the second harmonic and basic harmonic of Stokes second-order wave theory (e.g. Greenwood and
Davis, 2011), respectively; $H_{\mathrm{w}}$ is the significant wave height; $L_{\mathrm{W}}$ is the wavelength; $k_{\mathrm{W}}=2 \pi / L_{\mathrm{w}}$ is the wave number; and $h$ is the water depth. When waves propagate into shallow waters, $\gamma_{\mathrm{w}}$ becomes more significant, as the term $1 / \sinh ^{3}\left(k_{\mathrm{w}} h\right)$ increases when decreasing $h$. At a given depth, $\gamma_{\mathrm{w}}$ tend to be higher for longer incident waves. This effect may be explained by the fact that longer waves propagate over a larger distance in limited water depth $(h<L / 2)$ than shorter waves. Thus, they are more affected by wave-bottom interaction and, as a consequence, more asymmetric than shorter waves at the same depth.

To compute the sediment fluxes between grid cells, the components of the non-dimensional bed load transport vector are rotated to the grid referential ( $u$-axis and $v$-axis):

$\Phi_{u}=\Phi_{\|} \cos \varnothing_{c}-\Phi_{\perp} \sin \varnothing_{c}$,

$\Phi_{v}=\Phi_{\|} \sin \varnothing_{c}+\Phi_{\perp} \cos \varnothing_{c}$,

where $\varnothing_{c}$ is the angle between the horizontal velocity vector and the $u$-axis. Thus, the bed load transport vector, $\boldsymbol{q}=$ $\left(q_{u} q_{v}\right)$, in mass units $\left(\mathrm{kg} \mathrm{m}^{-1} \mathrm{~s}^{-1}\right)$ is equal to

$q_{u}=\rho_{\mathrm{s}} \Phi_{u}\left[g\left(\rho_{\mathrm{r}}-1\right) d^{3}\right]^{1 / 2}$,

$q_{v}=\rho_{\mathrm{s}} \Phi_{v}\left[g\left(\rho_{\mathrm{r}}-1\right) d^{3}\right]^{1 / 2}$,

where $\rho_{\mathrm{s}}$ is the sand particle density $\left(\mathrm{kg} \mathrm{m}^{-3}\right) ; \rho_{\mathrm{r}}$ is the relative density $\left(\rho_{\mathrm{s}} / \rho\right)$; and $d$ is the sand representative diameter (m).

\subsection{Bed slope correction}

Wave action induces a shoreward sediment transport that has no counterpart in 2DH models, leading to sand accumulation in the nearshore and increasing the steepness of the beach profile. Actually, undertow currents are responsible for a seaward sediment transport, which may generate sandbars. Diverse opposing forces are responsible for creating an equilibrium profile, which depends on sediment characteristics and wave heights (Dean, 1991). To account for the neglected forces in 2DH models, we defined a maximum slope $\left(\alpha_{\max }\right)$ that when exceeded induces sediment transport in the downslope direction. This artificial sediment transport may act as the undertow, transporting sediment seaward. The mass of sand $(M)$ in the sediment column and, consequently, the bathymetry are updated when the bottom slope $(\alpha)$ is larger than $\alpha_{\max }$ :

$M_{i, j}^{t+1}=M_{i, j}^{t}-\Delta M$,

$M_{i, j+1}^{t+1}=M_{i, j+1}^{t}+\Delta M$,

where

$\Delta M=\Delta z_{\mathrm{b}} A \rho_{\mathrm{S}}(1-n), \quad \alpha>\alpha_{\max }$

$\Delta M=0, \quad \alpha \leq \alpha_{\max }$

in which $n$ is the sediment porosity, $A$ is the grid cell area, $t$ is an index symbol for time, and $i, j$ are index symbols to 
identify the grid cell ( $i$ - line number; $j$-column number). Considering the $u$-direction, the bed change in one time step $\left(\Delta z_{\mathrm{b}}\right)$ is computed as

$$
\begin{aligned}
& \Delta z_{\mathrm{b}}=\min \left(\left(|\alpha|-\alpha_{\max }\right) \Delta x, \Delta z_{\mathrm{b}_{\max }}\right), \alpha>0 \\
& \Delta z_{\mathrm{b}}=\min \left(-\left(|\alpha|-\alpha_{\max }\right) \Delta x,-\Delta z_{\mathrm{b}_{\max }}\right), \alpha<0
\end{aligned}
$$

where $\alpha=\left(z_{\mathrm{b}_{i, j+1}}-z_{\mathrm{b}_{i, j}}\right) / \Delta x, \Delta x$ is the cell width, $z_{\mathrm{b}}$ is the distance from the bed to a reference height (e.g. the hydrographic zero), and $\Delta z_{\mathrm{b}_{\max }}$ is a threshold to avoid numerical instabilities due to large shockwaves. Similar equations are used in the $v$-direction. Different values of the maximum slope $\left(\alpha_{\max }\right)$ can be defined in wet and dry cells. This method is based on that of Roelvink et al. (2009), previously applied to simulate dune erosion. The method was implemented in the MOHID code in terms of mass evolution, in order to be applied in the future considering multiple sediment fractions. The shoreline position is also updated following this approach. Other authors have used the same approach to simulate the migration of a tidal inlet (Nahon et al., 2012; Fortunato et al., 2014).

\subsection{Model coupling}

The wave-induced force (radiation stress) computed by the SWAN wave model is provided to the MOHID hydrodynamic model in order to simulate the wave-induced currents and wave set-up. Fields of significant wave height, wave period, wavelength, wave direction, and maximal orbital velocity near the bottom are also provided by SWAN to MOHID in order to compute the bed shear stress and sediment transport. On the other hand, the MOHID hydrodynamic model returns fields of water level and current to SWAN. The water level variation caused by the tidal motion changes the breaker zone and shoreline position, affecting waves and sediment transport. The morphological evolution modifies the currents and waves. Thus, the bathymetry changes computed by MOHID are also updated in SWAN. The different fields computed by SWAN must be updated in MOHID, and the different fields computed by MOHID must be updated in SWAN, with an adequate frequency for each application depending on the variability of forcing conditions and the speed of morphological changes.

The coupling between the MOHID modelling system and the SWAN wave model was performed by files transferring through tools developed in the Fortran language to convert the results to the appropriate format and another tool developed in the Python language to automatically manage the runs of the tools and models. At this time, we have focused on model results instead of numerical efficiency. However, considering the domain decomposition parallelisation approach implemented using MPI directives and the morphological acceleration factor, the computational time required to simulate the presented test cases was feasible through the use of a regular computer with six cores.

\section{Test cases}

\subsection{Coastal defence structures}

The morphological evolution of a schematic beach was simulated to assess model results, considering the beach response for different designs of detached breakwaters and groynes. Constant wave conditions were defined along the offshore boundary ( $1.5 \mathrm{~m}$ of wave height, $8 \mathrm{~s}$ of peak wave period, and $15^{\circ}$ of peak wave direction), following the JONSWAP spectrum. The hydrodynamic model was applied in 2DH mode, considering the vertically integrated wave-induced forces. The MOHID domain was defined as $2 \mathrm{~km}$ cross-shore by $3 \mathrm{~km}$ alongshore, whereas the SWAN domain was defined as $2 \mathrm{~km}$ cross-shore by $9 \mathrm{~km}$ alongshore $(3 \mathrm{~km}$ larger on each side of the MOHID domain). The grid resolution was equal in both models, ranging from $50 \mathrm{~m} \times 50 \mathrm{~m}$ to $10 \mathrm{~m} \times 10 \mathrm{~m}$. A larger domain for the wave model was considered to avoid inaccuracies in the lateral boundaries (shadow zones), as incident wave energy was imposed only along the offshore boundary. To prevent discontinuities in the SWAN bathymetry, the part of the domain not covered by the MOHID domain was updated with the depths of the MOHID cross-shore boundaries. The bathymetry evolution was allowed only after a warm-up period, considering a morphological acceleration factor of 365. This means that 1 day of simulation time is equivalent to 1 year of morphological changes. The wave forcing was updated in MOHID, as the bathymetry and water levels were updated in SWAN, with a constant frequency of $5 \mathrm{~min}$ (or $30 \mathrm{~h}$ of morphological evolution).

The open boundary condition was defined as a null gradient for the sediment concentrations in the water column, as well as for the sediment mass evolution at the bed (or, equivalently, for bathymetry). A null gradient condition was also imposed at the open boundaries for the normal and tangential current velocities. The radiation condition of Blumberg and Kantha (1985) was imposed for water level, Eq. (3), assuming a passive condition at the cross-shore boundaries $\left(T_{d}=1 e^{32} \mathrm{~s}\right)$ and an active condition at the offshore boundary $\left(T_{d}=1 e^{-12} \mathrm{~s}\right)$. Thus, the water level was imposed at the offshore boundary as equal to the initial condition (zero in this case) to maintain the average water level inside the model domain; otherwise, it would continuously decrease. The effect of lateral friction in land boundaries was considered for a better representation of the flow around the groynes. The horizontal viscosity was set as $1.0 \mathrm{~m}^{2} \mathrm{~s}^{-1}$. The sand granulometry was uniform, with a diameter of $0.2 \mathrm{~mm}$.

The initial bathymetry was defined by considering an equilibrium profile of the form $h=\beta y^{2 / 3}$ (Dean, 1991), where $\beta$ is a constant set to $0.12 \mathrm{~m}^{1 / 3}$, and $y$ is the distance to the shoreline. The average slope is approximately $1: 60$ in the first $200 \mathrm{~m}$ from the shoreline, decreasing seaward. The maximum slope $\left(\alpha_{\max }\right)$ was defined as $1: 50$ for the bed slope corrections. The effectiveness of the bed slope correction 

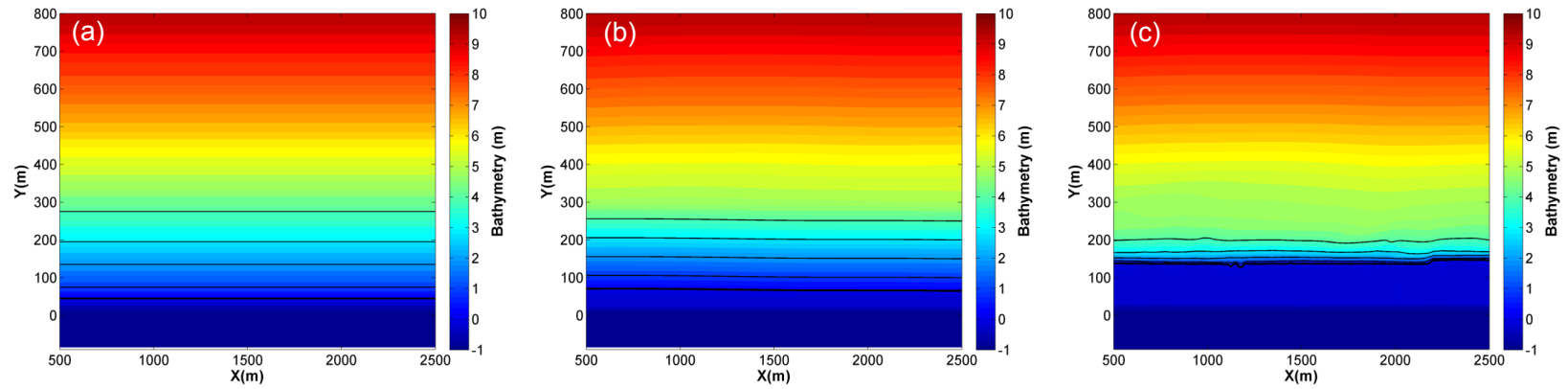

Figure 1. Initial bathymetry (a) and bathymetries after 9 years of morphological evolution considering the bed slope correction (b) and without the bed slope correction (c). The thicker isoline in the bathymetry represents the shoreline, whereas the remaining ones represent the $1,2,3$, and $4 \mathrm{~m}$ isobaths.

Table 1. Detached breakwaters considered for test case scenarios.

\begin{tabular}{rrrl}
\hline Length & Distance & Ratio $(r)$ & Beach response* \\
\hline 100 & 500 & 0.2 & Salient \\
100 & 200 & 0.5 & Salient \\
200 & 200 & 1.0 & Salient/tombolo \\
200 & 100 & 2.0 & Tombolo \\
\hline
\end{tabular}

* Beach response according to Dally and Pope (1986).

was first assessed neglecting coastal defence structures. The bathymetry of the schematic beach shows minor adaptations to the wave regime after 9 years of morphological evolution considering the maximum bed slope, whereas without the bed slope correction the bathymetry reaches unrealistically steep slopes and sand accumulation on the beach (Fig. 1).

\subsubsection{Detached breakwaters}

Detached breakwaters generate sediment transport from the adjacent coast to the lee side of the structure, leading to the formation of a bulge or salient in the beach planform. Depending on geometrical features of the breakwater, wave climate, and sediment availability, the salient may become attached to the breakwater, forming a tombolo. Based on the analysis of several existing breakwater projects, Dally and Pope (1986) found that a ratio $(r)$ between the breakwater's length and a distance to the shoreline of less than 0.5 prevents the development of a tombolo. In contrast, the development of a tombolo is assured if $r$ is larger than 1.5, assuming sufficient sediment supply. Taking these values into account, we tested the model response for the four different detached breakwater designs described in Table 1.

Model results for a near-equilibrium planform of the shoreline agree with the analysis of Dally and Pope (1986), demonstrating the development of a salient for $r$ equal to 0.2, 0.5, and 1.0 (Figs. 2, 3, and 4), which become attached to the breakwater, forming a tombolo only for $r$ equal to 2.0 (Fig. 5). The obliquity of waves generates a longshore current and, consequently, longshore sediment transport in the nearshore zone. The shoreline tends to be parallel to the wave crests, creating asymmetric bulges. For $r$ equal to 0.5 and 1.0, longshore currents restricted the size of the salients, preventing the connection with the breakwater. The shoreline advances more on the updrift side for larger values of $r$, trapping sediment from the littoral drift. On the other hand, the downdrift beach erosion increases. When a tombolo is formed, the detached breakwater affects the shoreline similarly to a groyne.

\subsubsection{Groynes}

Groynes are applied to reduce the littoral drift in the surf zone, trapping sediment on the updrift side of the structure, which may cause erosion problems on the downdrift side. Moreover, the longshore currents are forced to deviate into deeper water around groynes, causing sediment losses from nearshore to offshore. The morphological impacts of the groynes are a function of their length from the shoreline. Model results were assessed for two designs of groynes, with lengths of 100 and $200 \mathrm{~m}$ (Figs. 6 and 7). As expected, greater erosion occurs on the downdrift side for a longer groyne, as more sediment from the littoral drift gets trapped on the updrift side. Furthermore, offshore sediment transport becomes intensified in the $200 \mathrm{~m}$ length groyne design, as the deviation of longshore currents is more important. In this case, the retrogradation of the shoreline is similar to the case of a detached breakwater in which a tombolo was formed.

\subsection{Sandbars formation}

In this test case, we verified the model capacity to generate sandbars in a 3-D approach. The same domain and sand granulometry $(0.2 \mathrm{~mm})$ as in the previous $2 \mathrm{DH}$ test cases were considered, but without protection structures. Two wave heights $(1.5$ and $1.0 \mathrm{~m})$ were defined in sequence along the offshore boundary during periods of 45 days of morphological evolution ( $3 \mathrm{~h}$ of simulation time with a morphological acceleration factor of 365). The peak wave period and 

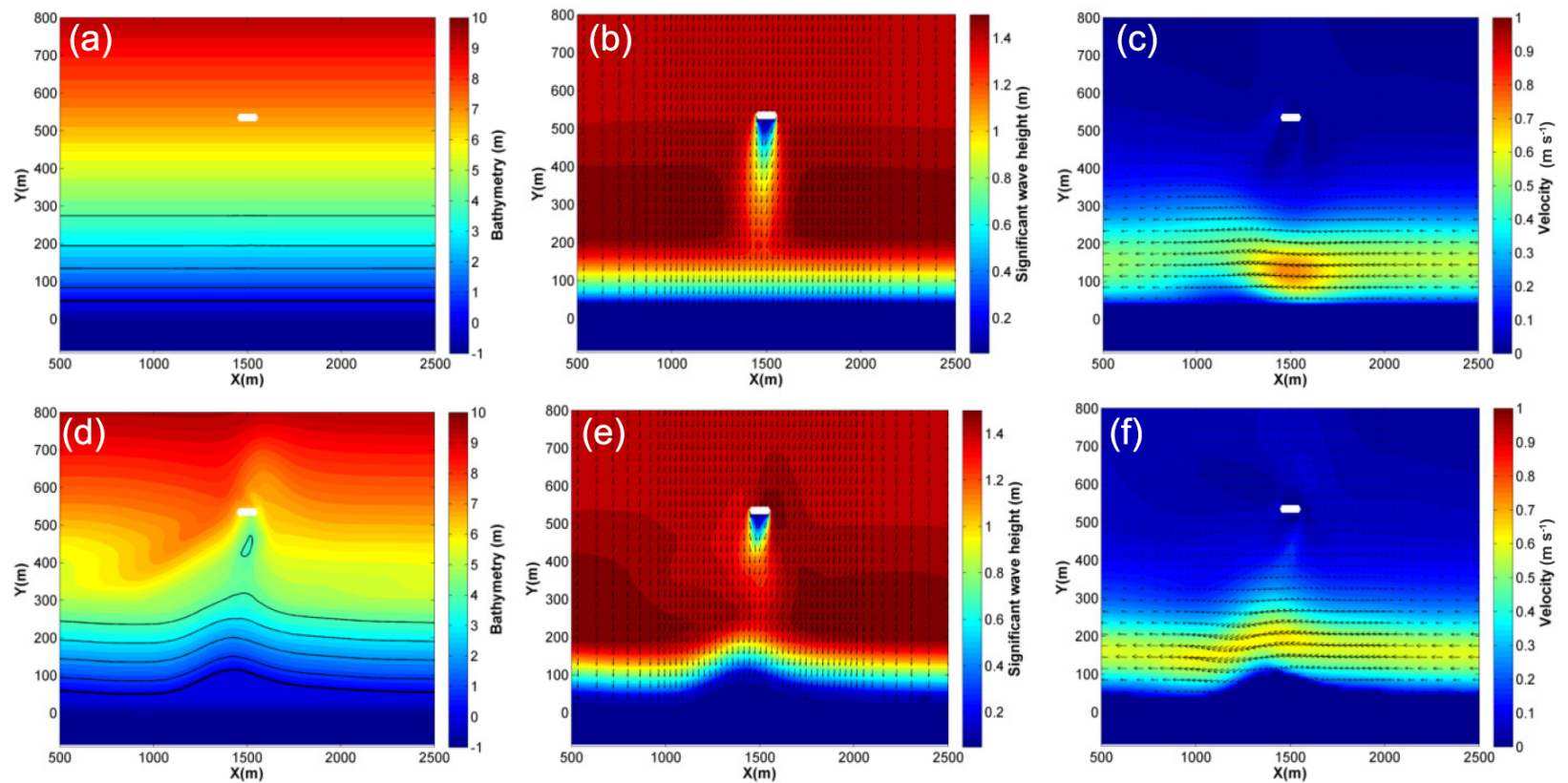

Figure 2. Model results for the breakwater's length-to-distance ratio of 0.2. Bathymetry (a, d), waves (b, e), and currents (c, f) for the initial condition $(\mathbf{a}, \mathbf{b}, \mathbf{c})$ and near equilibrium $(\mathbf{d}, \mathbf{e}, \mathbf{f})$ after 9 years. The thicker isoline in the bathymetry represents the shoreline, whereas the remaining ones represent the $1,2,3$, and $4 \mathrm{~m}$ isobaths.
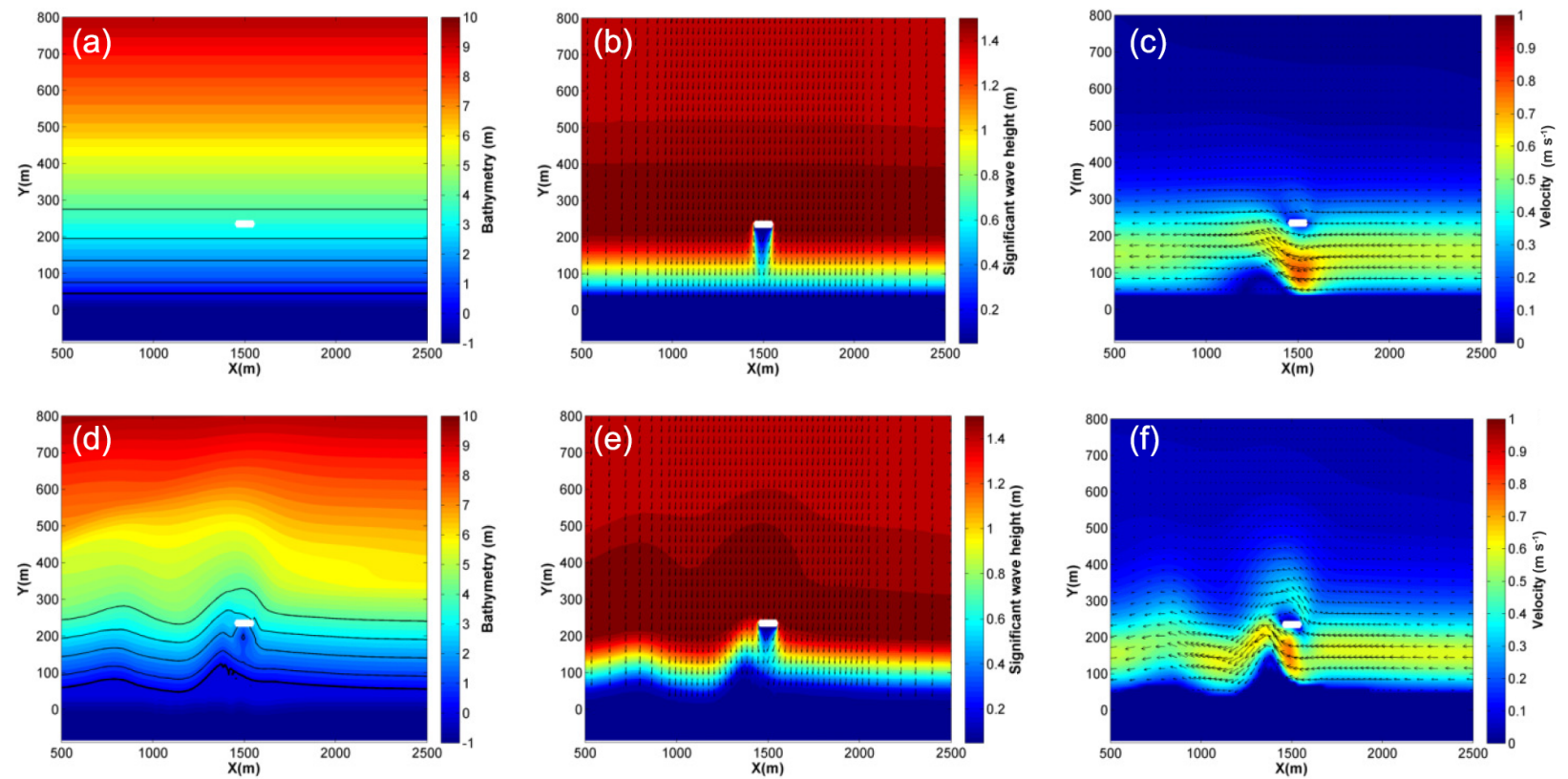

Figure 3. Model results for the breakwater's length-to-distance ratio of 0.5 . Bathymetry $(\mathbf{a}, \mathbf{d})$, waves $(\mathbf{b}, \mathbf{e})$, and currents (c, f) for the initial condition $(\mathbf{a}, \mathbf{b}, \mathbf{c})$ and near equilibrium $(\mathbf{d}, \mathbf{e}, \mathbf{f})$ after 18 years. The thicker isoline in the bathymetry represents the shoreline, whereas the others represent the $1,2,3$, and $4 \mathrm{~m}$ isobaths.

peak wave direction were maintained constant $\left(8 \mathrm{~s}\right.$ and $\left.15^{\circ}\right)$. For the 3-D case, a larger maximum slope was defined as $1: 10$ for the bed slope corrections, considering that the seaward sediment transport due to undertow currents can now be represented. The maximum slope in 3-D simulations is use- ful for representing the sand motion induced by excessively steep slopes.

The water column was divided into five layers of a sigma vertical coordinate and a simple exponential approach was followed to consider the vertical variation of the wave- 

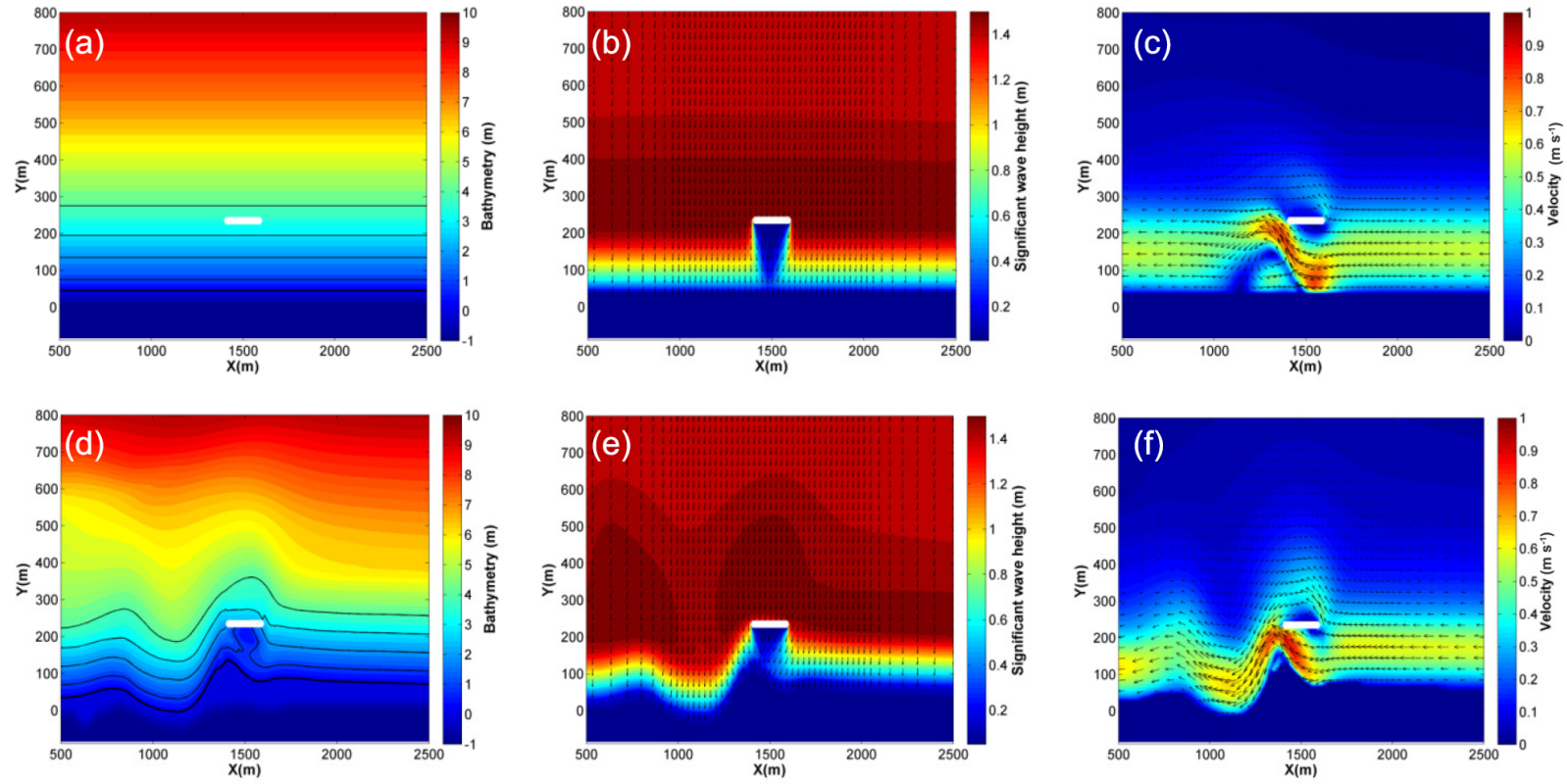

Figure 4. Model results for the breakwater's length-to-distance ratio of 1.0. Bathymetry (a, d), waves (b, e), and currents (c, f) for the initial condition $(\mathbf{a}, \mathbf{b}, \mathbf{c})$ and near equilibrium $(\mathbf{d}, \mathbf{e}, \mathbf{f})$ after 27 years. The thicker isoline in the bathymetry represents the shoreline, whereas the others represent the $1,2,3$, and $4 \mathrm{~m}$ isobaths.
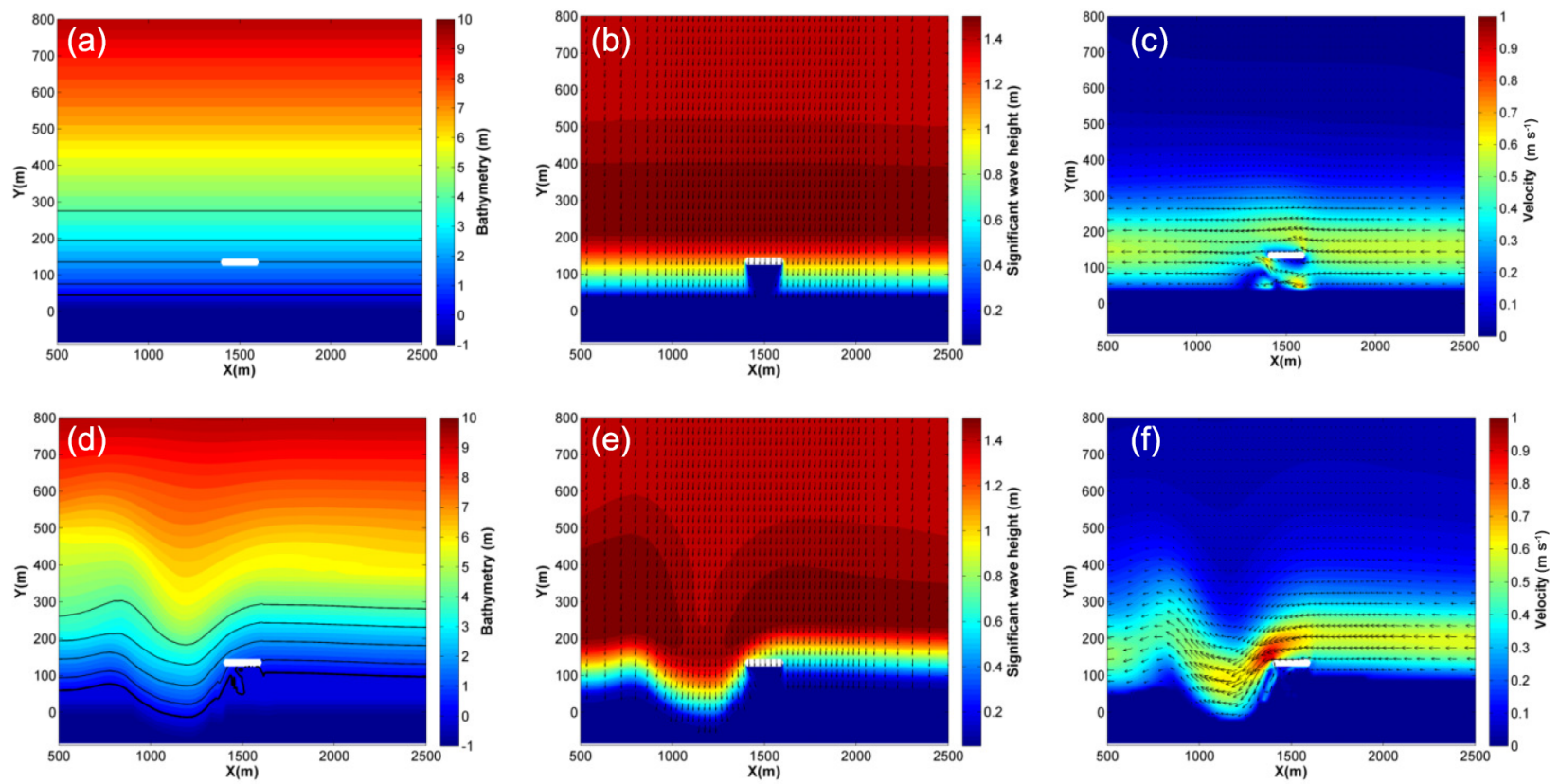

Figure 5. Model results for the breakwater's length-to-distance ratio of 2.0. Bathymetry (a, d), waves (b, e), and currents (c, f) for the initial condition $(\mathbf{a}, \mathbf{b}, \mathbf{c})$ and near equilibrium $(\mathbf{d}, \mathbf{e}, \mathbf{f})$ after 18 years. The thicker isoline in the bathymetry represents the shoreline, whereas the others represent the $1,2,3$, and $4 \mathrm{~m}$ isobaths.

induced forces: an exponential decrease in the radiation stress is imposed from the surface to the bottom, following the same shape as the profile of the orbital velocities, provided by the linear wave theory. The vertical radiation stress profile is designed to conserve the vertically integrated flux of momentum, which remains equal to the flux given by SWAN. The effects of wave breaking on vertical turbulence were disregarded in this work. The idea here is only to provide an approximate representation of the vertical distribution of wave momentum, in order to generate a general 

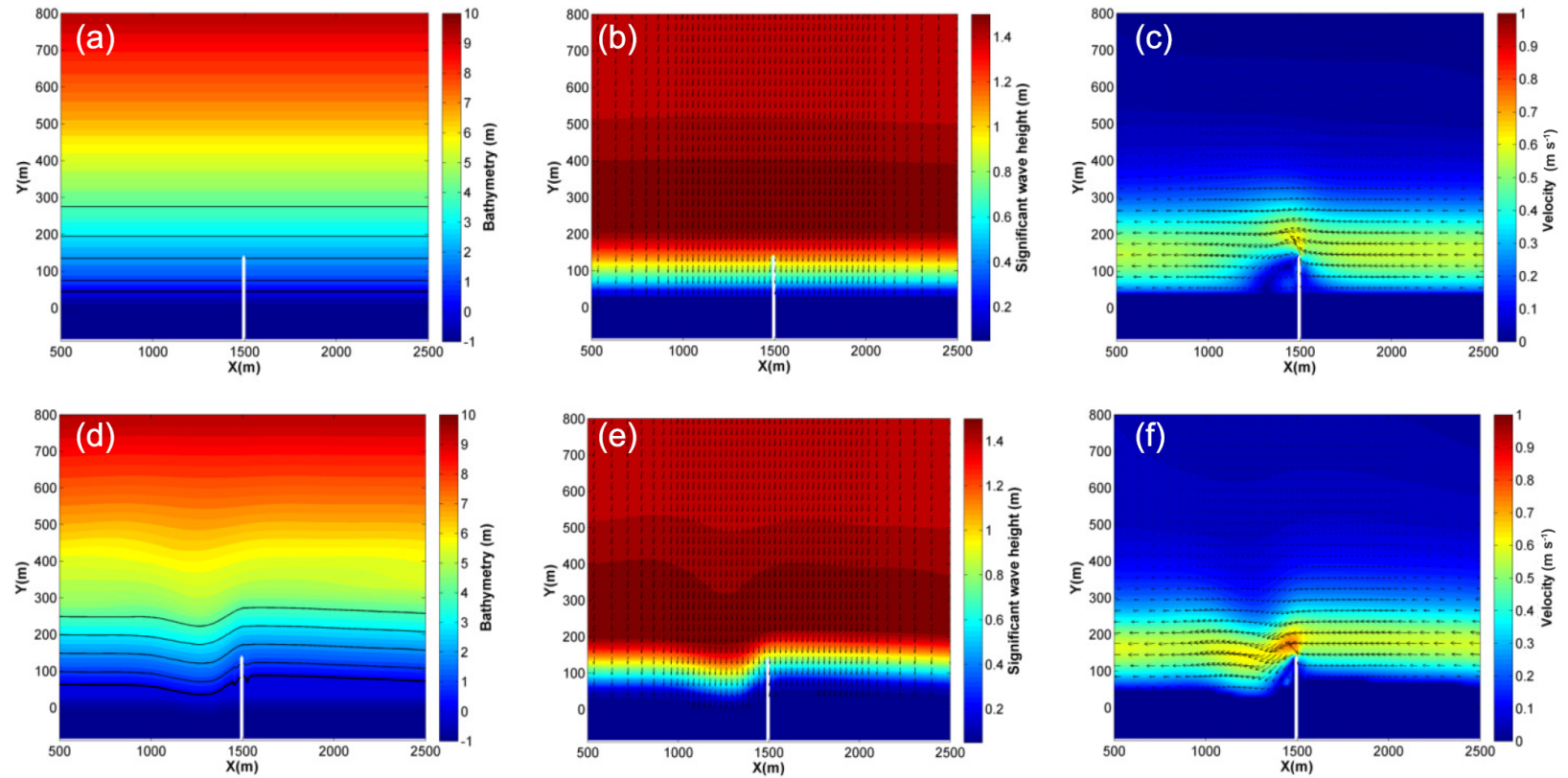

Figure 6. Groyne with a length of $100 \mathrm{~m}$ from the shoreline. Bathymetry $(\mathbf{a}, \mathbf{d})$, waves $(\mathbf{b}, \mathbf{e})$, and currents $(\mathbf{c}, \mathbf{f})$ for the initial condition $(\mathbf{a}$, b, c) and near equilibrium (d, e, f) after 9 years. The thicker isoline in the bathymetry represents the shoreline, whereas the others represent the $1,2,3$, and $4 \mathrm{~m}$ isobaths.
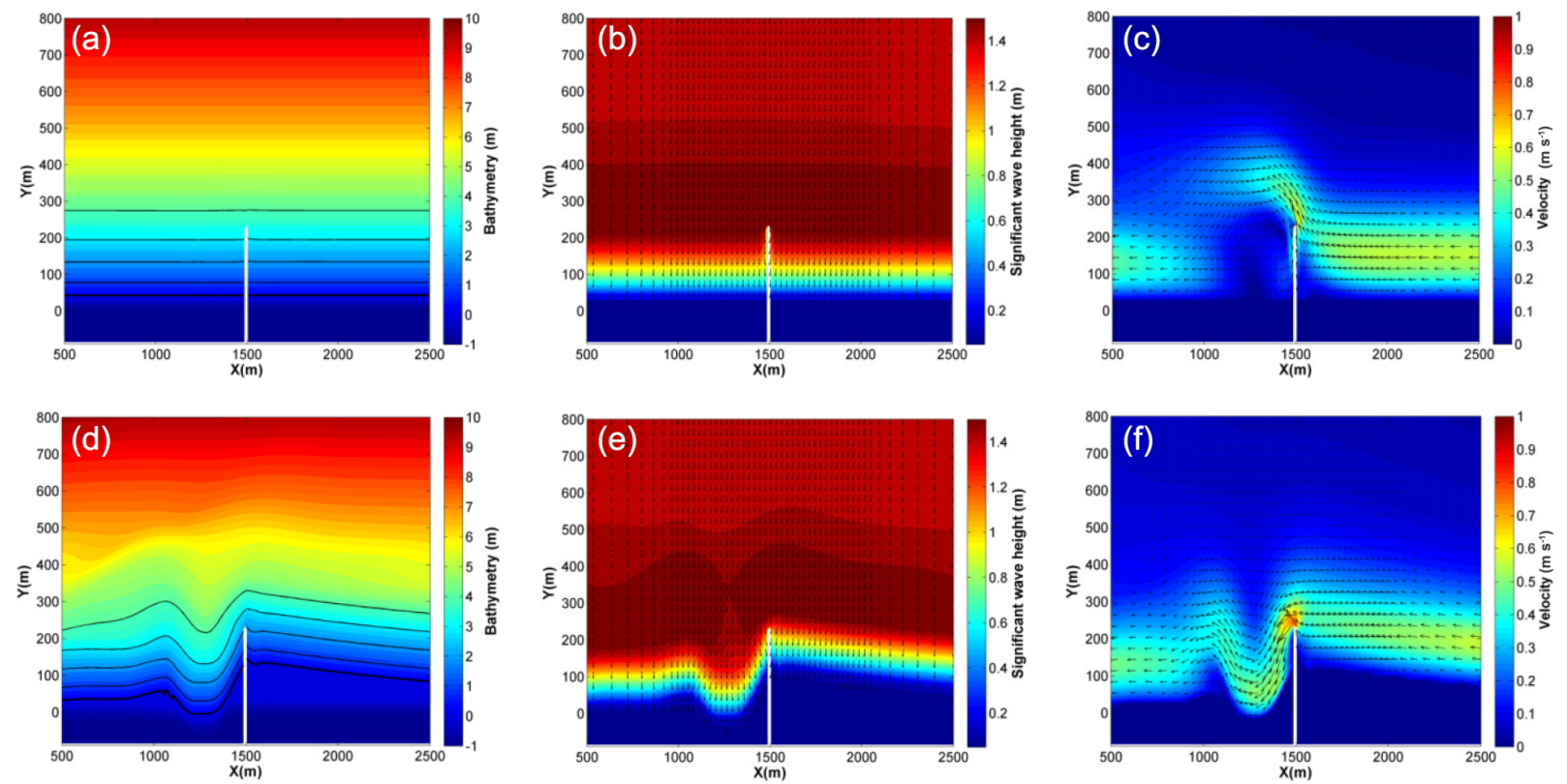

Figure 7. Groyne with a length of $200 \mathrm{~m}$ from the shoreline. Bathymetry (a, d), waves (b, e), and currents (c, f) for the initial condition (a, $\mathbf{b}, \mathbf{c})$ and near equilibrium $(\mathbf{d}, \mathbf{e}, \mathbf{f})$ after 9 years. The thicker isoline in the bathymetry represents the shoreline, whereas the others represent the $1,2,3$, and $4 \mathrm{~m}$ isobaths.

undertow pattern. Thus, the corresponding results should be considered as a first qualitative evaluation of the effect of such an undertow in our morphological module, the latter being our focus here. It is left for further work to use a more advanced formulation of 3-D wave-current interactions for more quantitative investigations. The $k-\varepsilon$ turbulence-closure model was used to compute the vertical viscosity, with the MOHID default parameterisation, whereas the horizontal viscosity was set to $1.0 \mathrm{~m}^{2} \mathrm{~s}^{-1}$. 

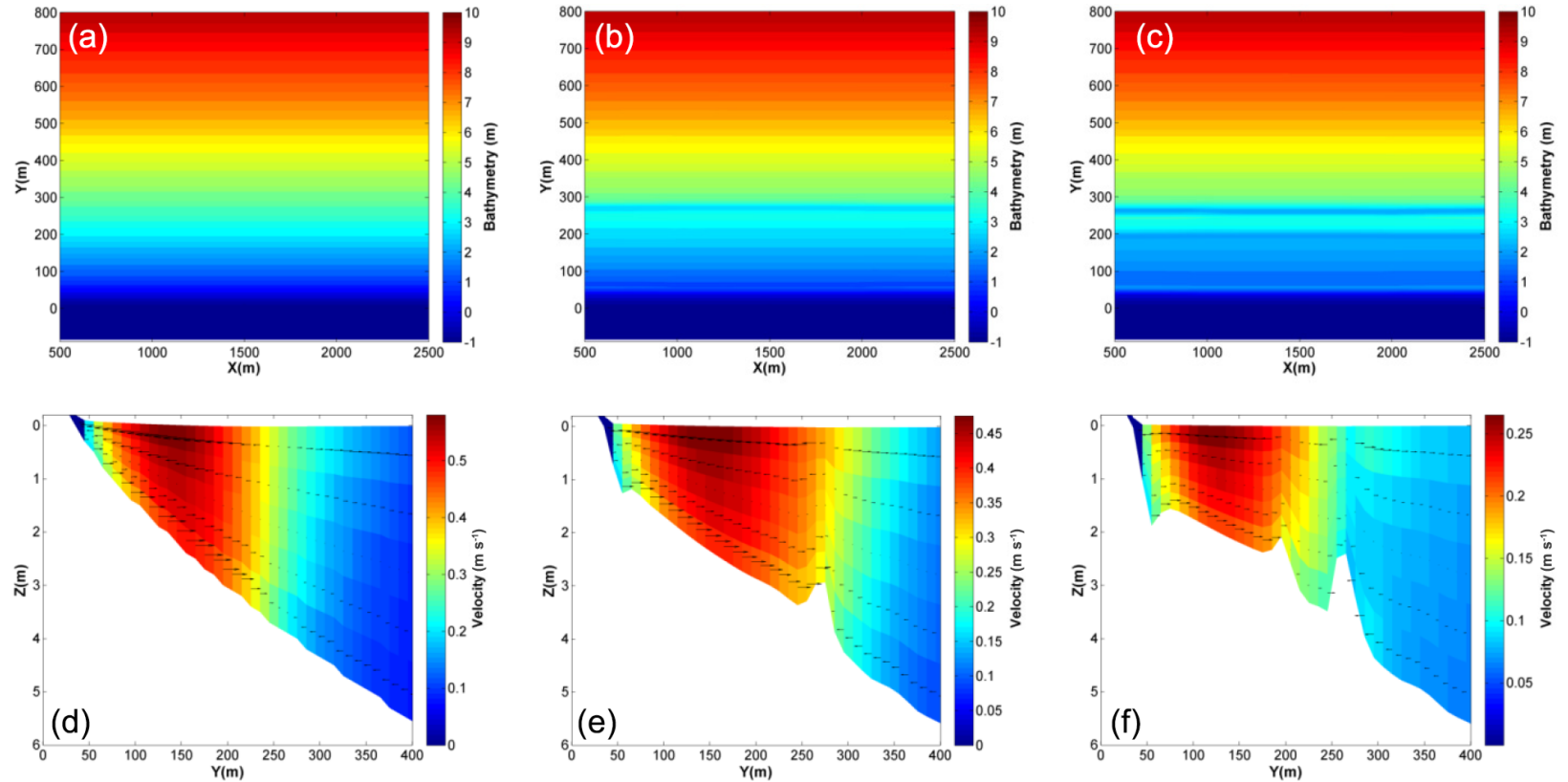

Figure 8. Simulated sandbars for different wave heights. The horizontal plane of the bathymetry (a, b, c) and a vertical cut with velocity modulus and vectors (d, e, f). (a, d) Initial condition. (b, e) After 45 days of morphological evolution with $1.5 \mathrm{~m}$ wave height. (c, f) After an additional 45 days of morphological evolution with $1.0 \mathrm{~m}$ wave height.

(a)

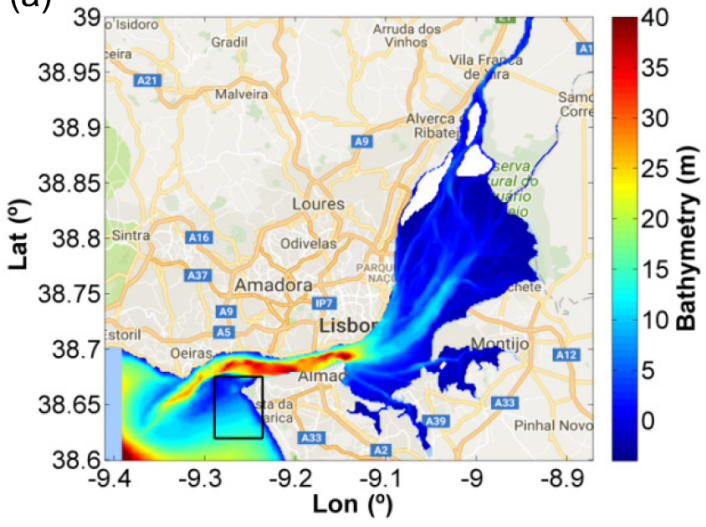

(b)

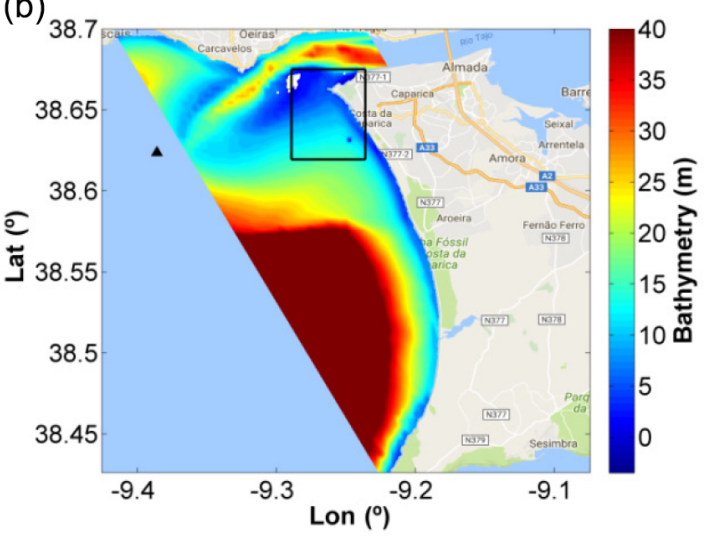

Figure 9. Bathymetries of the Tagus Estuary hydrodynamic model (a) and the wave model (b) created to propagate the waves until the Tagus Estuary mouth. The domain of the Costa da Caparica model is presented by the black rectangle and the location of the port of Lisbon wave buoy is indicated by the black triangle.

The open boundary conditions for sediment concentrations in the water column and sediment mass evolution at the bed column were defined as a null gradient, as well as the boundary conditions for normal and tangential velocities, as in the previous 2DH test cases. Considering that no structures were included in this test case, the bathymetry evolution was expected to be nearly uniform along the beach. Thus, a cyclic boundary condition was imposed at the cross-shore boundaries together with a Flather radiation condition at the offshore boundary (Eq. 4).
The model was capable of representing an undertow pattern and associated sediment transport that induce the formation of longshore sandbars (Fig. 8). A longitudinal current is presented in the surf zone, similarly to that observed in $2 \mathrm{DH}$. However, a cross-shore velocity component is now represented by the 3-D model. Inside the surf zone, this component is shoreward near the surface and seaward near the bottom. As expected, the cross-shore component has opposite directions before and after the breaking zone. The sandbar migrated seaward, changing the location of the breaking zone until wave heights decreased to $1.0 \mathrm{~m}$ after 45 days. 

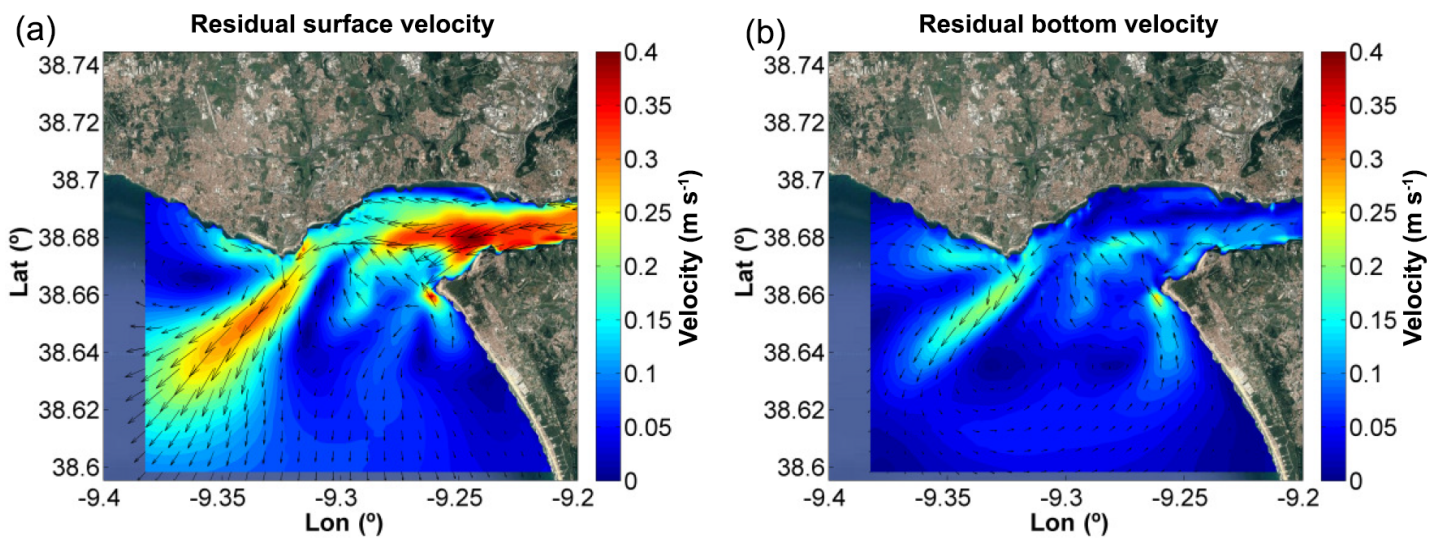

Figure 10. Residual velocity in the Tagus Estuary mouth at the surface (a) and near the bottom (b) obtained from the 3-D baroclinic model for the Tagus Estuary.
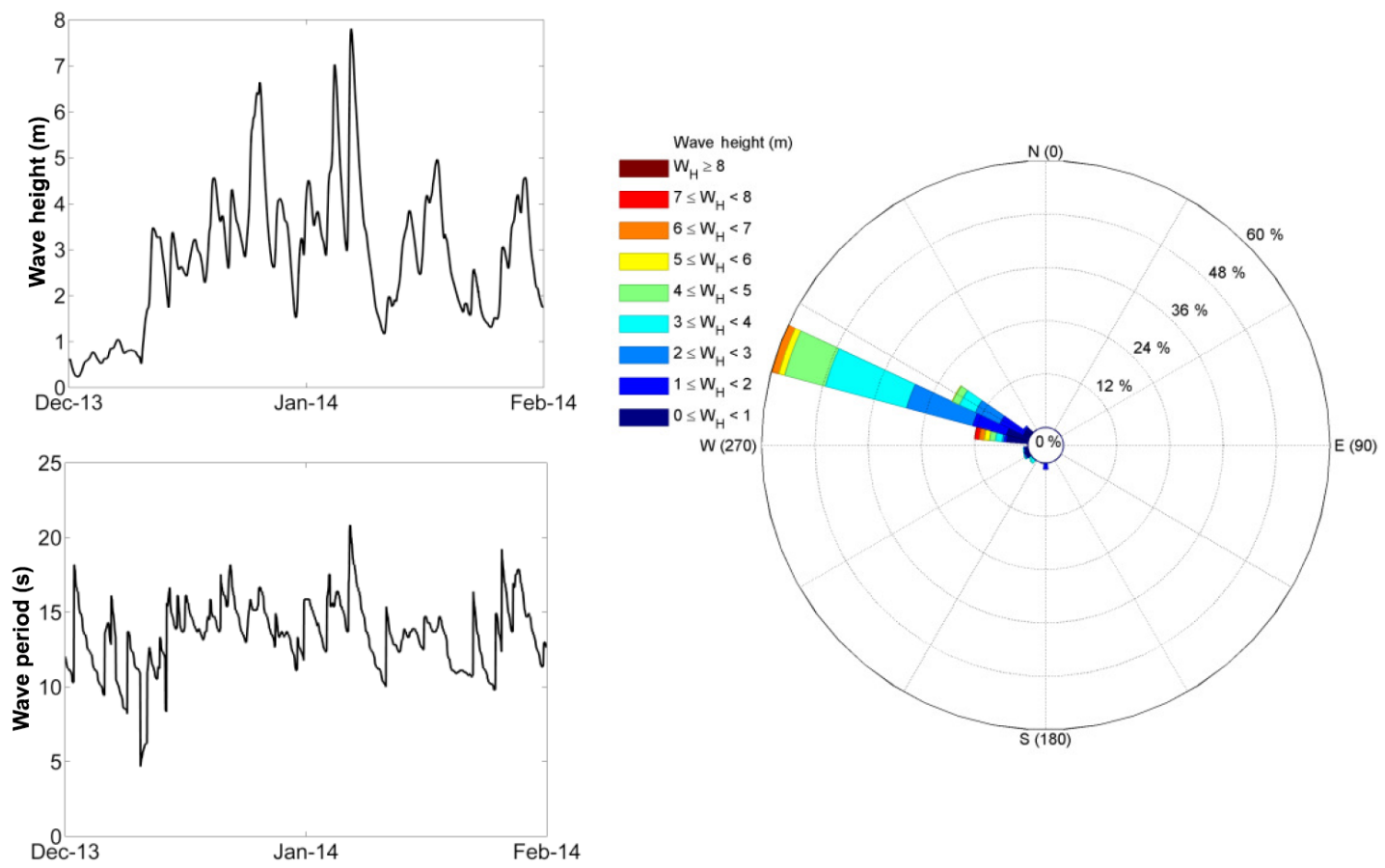

Figure 11. Wave conditions for the winter of 2013/2014 obtained from the Portuguese coast wave model in the location of the port of Lisbon wave buoy.

At this time, waves were able to propagate further without breaking, creating a new sandbar nearer the coast. Finally, the results demonstrate the model's potential to represent the formation of multiple sandbars, which are observed in many places (e.g. Dolan and Dean, 1985; Ruessink et al., 2009).

\subsection{Costa da Caparica}

The hydrodynamics and sediment transport on the southern coast of the Tagus Estuary mouth (Costa da Caparica) are evaluated under extreme wave conditions by coupling the MOHID modelling system and the SWAN wave model. A significant coastline retreat was observed in the Costa da Caparica in the last century. Defence structures (groynes) were built around the 1960s to reduce coastal erosion, resulting in some stability until the 2000/2001 winter, when this issue started to receive more attention from the local authorities (Veloso-Gomes et al., 2009). The importance of the problem has augmented due to urbanisation and tourism development. The location near to the Tagus Estuary inlet increases the complexity of sediment dynamics in this zone.

A downscaling approach was followed to provide appropriate boundary conditions for the Costa da Caparica model, considering previous results of the wave and hydrodynamic 
(a) 2014-1-6 $16 \mathrm{~h}$

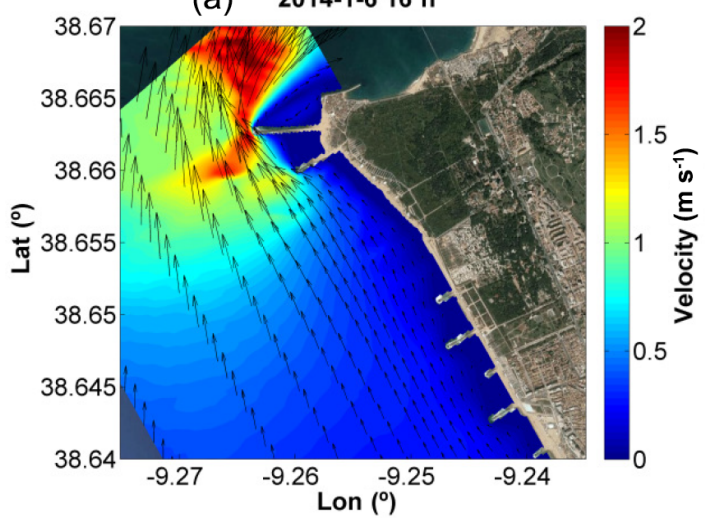

(c) 2014-1-6 $16 \mathrm{~h}$

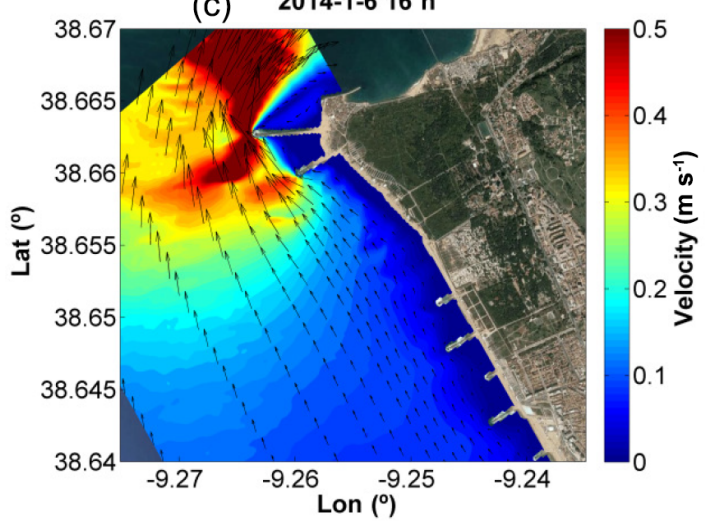

(b) 2014-1-6 $22 \mathrm{~h}$

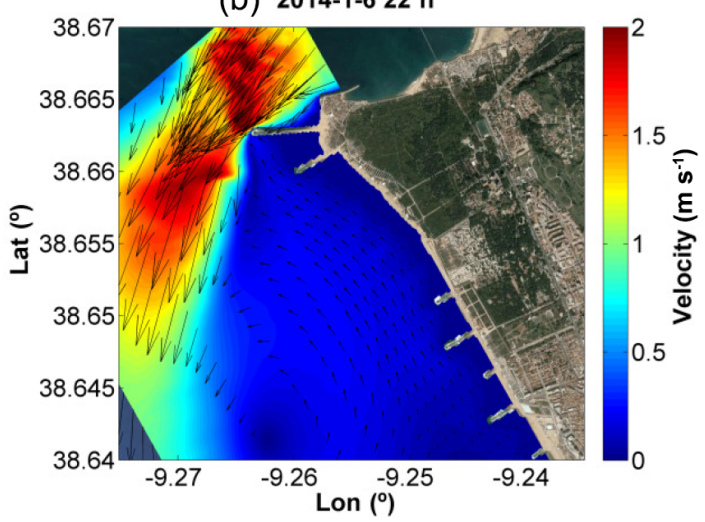

(d) 2014-1-6 $22 \mathrm{~h}$

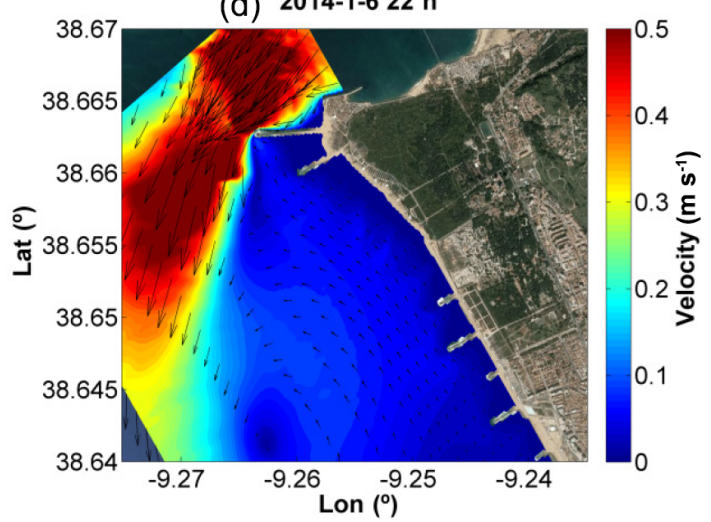

Figure 12. Velocity results of the Costa da Caparica model during flood $(\mathbf{a}, \mathbf{c})$ and ebb $(\mathbf{b}, \mathbf{d})$ tides at the surface $(\mathbf{a}, \mathbf{b})$ and near the bottom $(\mathbf{c}, \mathbf{d})$ without considering the wave's effect on the hydrodynamics.

(a) 2014-1-6 $16 \mathrm{~h}$

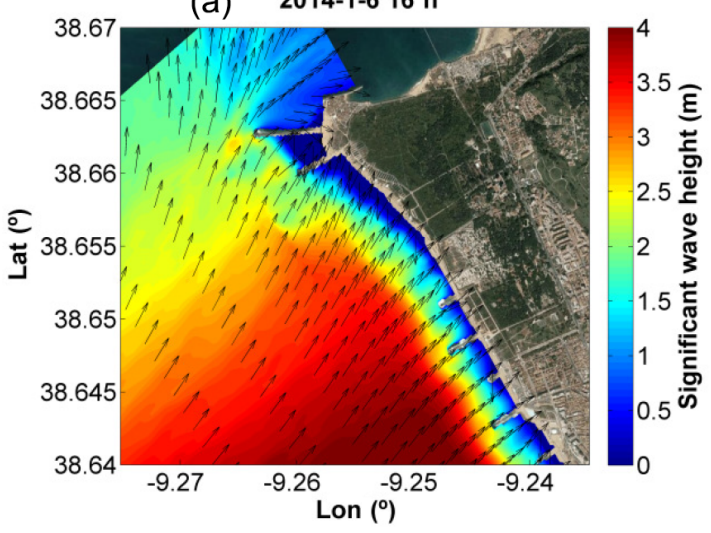

(b) 2014-1-6 $22 \mathrm{~h}$

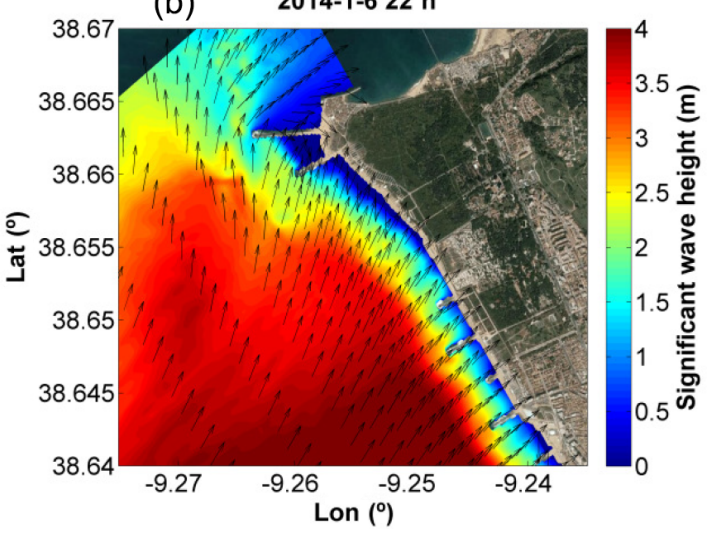

Figure 13. Wave results of the Costa da Caparica model.

modelling system for the Portuguese coast developed by the MARETEC research group (http://forecast.maretec.org). A new domain was created with $100 \mathrm{~m} \times 100 \mathrm{~m}$ of grid resolution to propagate the waves until the Tagus Estuary mouth. The bathymetries of the father hydrodynamic model and father wave model are presented in Fig. 9, showing the domain of the Costa da Caparica model. The hydrodynamic bound- ary conditions (water level, current velocities, salinity, and temperature) for the Costa da Caparica model were provided by the 3-D baroclinic model for the Tagus Estuary (see Franz et al., 2014a, b), through the application of the relaxation scheme together with the Flather radiation condition. The wave model for the Portuguese coast was validated previously considering the data of the port of Lisbon wave buoy, 
(a) 2014-1-6 $16 \mathrm{~h}$

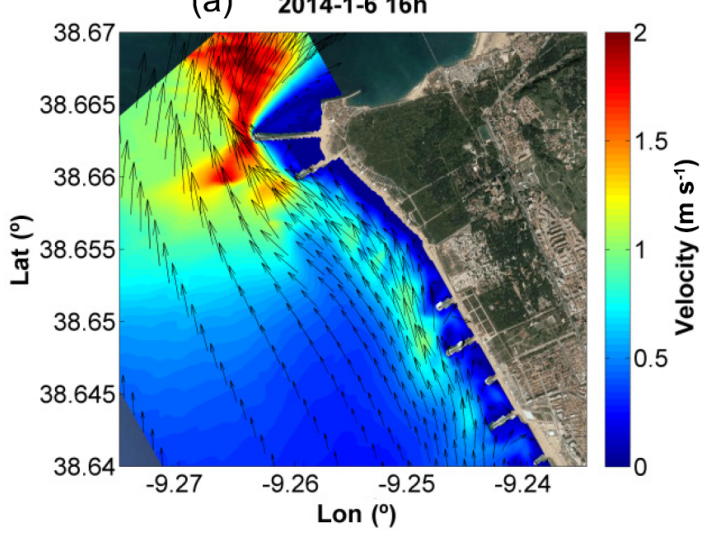

(c) 2014-1-6 16h

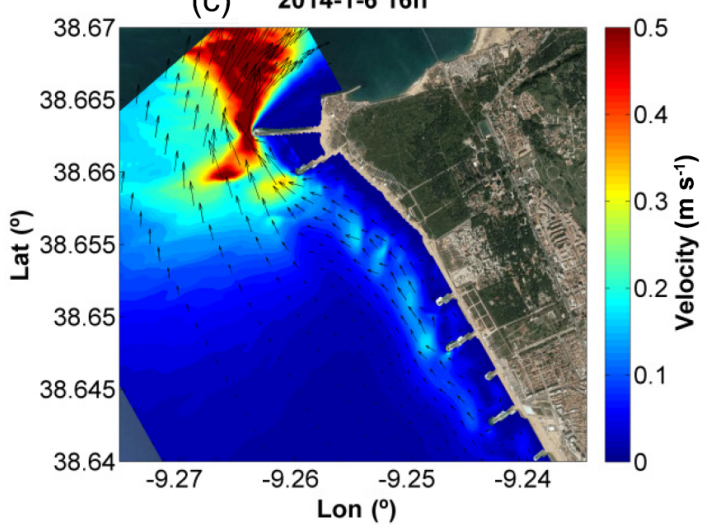

(b) $2014-1-622 \mathrm{~h}$

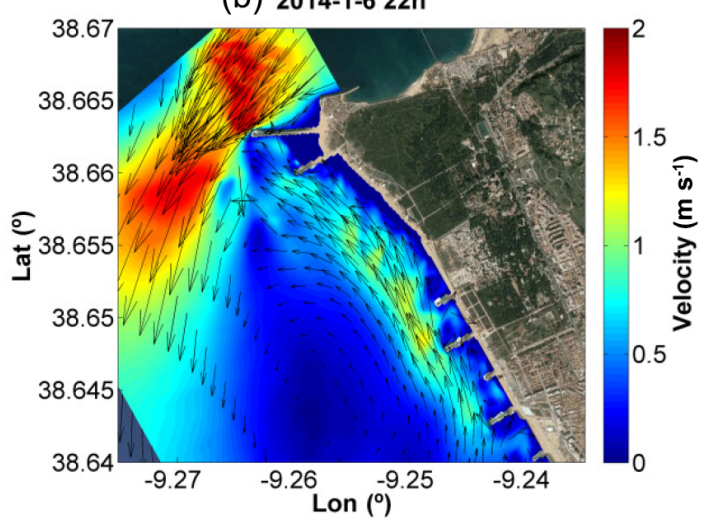

(d) 2014-1-6 22h

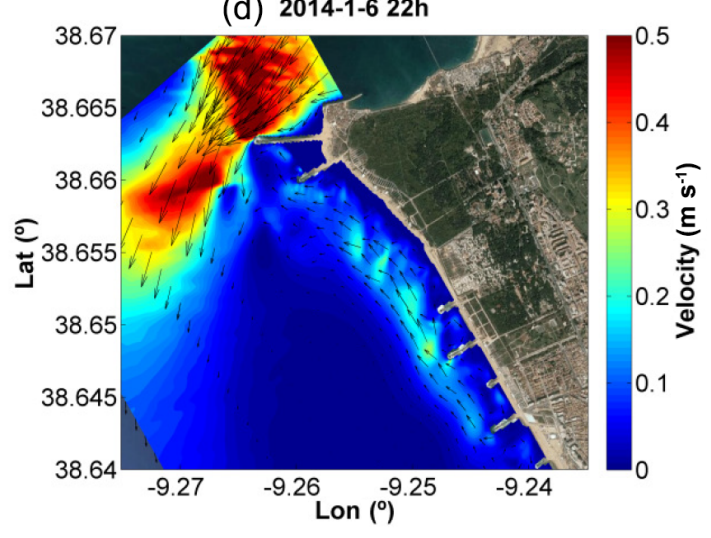

Figure 14. Velocity results of the Costa da Caparica model during flood (a, c) and ebb (b, d) tides at the surface (a, b) and near the bottom (c, d) considering the wave's effect on the hydrodynamics.

among other buoys located along the Portuguese coast (see Franz et al., 2014c).

The Tagus Estuary is classified as mesotidal, with an average tidal height of $2.0 \mathrm{~m}$ in the mouth (Lemos, 1972). The tide is the main mechanism forcing the flow in the estuary, determining current directions and water level variations (Franz et al., 2014d). The maximum velocities reach $2 \mathrm{~m} \mathrm{~s}^{-1}$ in the estuary mouth. The Tagus River is the estuary's main freshwater source, with an annual average flow of about $300 \mathrm{~m}^{3} \mathrm{~s}^{-1}$. The estuary stratification is strongly related to the river flow and tidal cycle. The residual currents pattern in the Tagus Estuary mouth is characterised by a jet in the inlet channel and two adjacent vortices, causing a residual recirculation into the estuary in front of the Costa da Caparica (Fig. 10).

The effects of the waves on the currents and sediment transport were investigated during a high-energy event in the winter of 2013/2014 caused by the Hercules storm. The wave conditions for the period of study in the location of the port of Lisbon wave buoy reached wave heights higher than $7 \mathrm{~m}$ and wave periods of up to $20 \mathrm{~s}$ (Fig. 11). A variable grid resolution was defined for the Costa da Caparica domain, ranging from 50 to $10 \mathrm{~m}$ near the coast. The water column was divided into 10 layers, including five layers in the first metre above the bottom with fixed thicknesses ranging from 0.1 to $0.3 \mathrm{~m}$, and five sigma layers on top. The exponential approach described in the last section was followed to represent the vertical variation of the wave-induced forces. The vertical viscosity was computed by the $k-\varepsilon$ turbulence-closure model and the horizontal viscosity was set to $5.0 \mathrm{~m}^{2} \mathrm{~s}^{-1}$. The bathymetry data for the coast of the Costa da Caparica were provided by the Portuguese Environment Agency (APA).

In a first scenario, the effects of the waves on the currents and sediment transport were neglected. Therefore, just the influence of hydrodynamic boundary conditions from the Tagus Estuary model was taken into account. The results of the Costa da Caparica model without the wave action demonstrate strong velocities of up to $2 \mathrm{~m} \mathrm{~s}^{-1}$ at the surface and $0.5 \mathrm{~m} \mathrm{~s}^{-1}$ near the bed in the northern zone, with opposite directions on the flood and ebb tides, whereas weak velocities are found in the remaining coast directed to the estuary inlet in both situations (Fig. 12). The strong tidal currents are deflected away from the shoreline by the presence of a long groyne.

During the period of study, the waves propagated from offshore, mainly with a west-northwesterly (WNW) direction 
(a) 2014-1-6 $16 \mathrm{~h}$

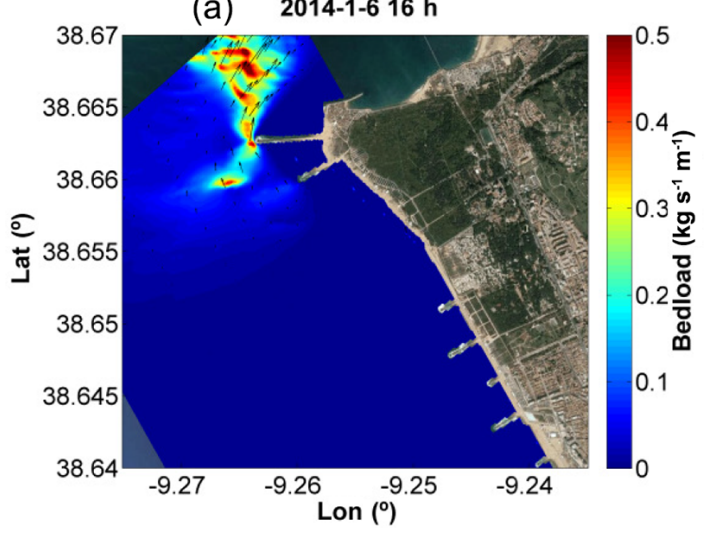

(c) 2014-1-6 $16 \mathrm{~h}$

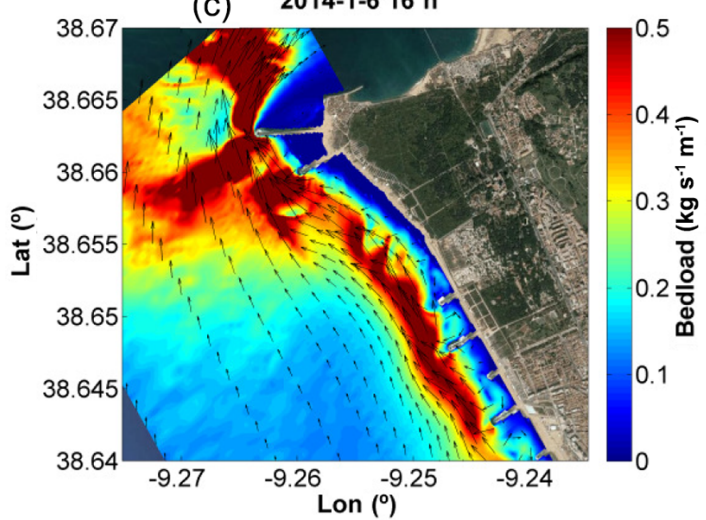

(b) 2014-1-6 $22 \mathrm{~h}$

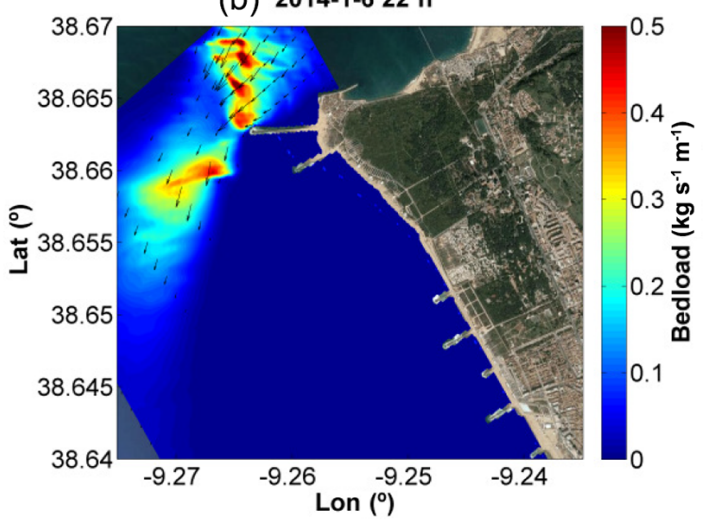

(d) 2014-1-6 $22 \mathrm{~h}$

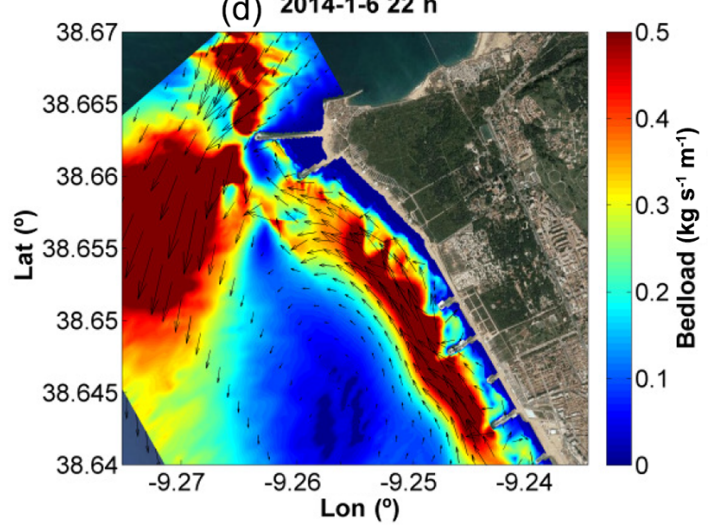

Figure 15. Results of bed load sediment transport for the scenarios without waves $(\mathbf{a}, \mathbf{b})$ and under extreme wave conditions (c, d).

(Fig. 11). The bathymetric features (Fig. 9) cause the modification of the wave propagation direction through refraction to a west-southwesterly (WSW) or southwesterly (SW) direction in the nearshore (Fig. 13). The effect of the currents and water level variations on wave propagation was also considered, with an update frequency of $1 \mathrm{~h}$, the same frequency at which the wave forcing was updated in MOHID. The oblique angle of the waves' incidence generates a nearshore longitudinal current oriented to the estuary inlet (Fig. 14), reinforcing the velocities observed in the scenario in which the wave action was neglected. The velocity vectors have a shoreward component at the surface, whereas near the bottom a seaward component is observed, caused by the vertical variation of the wave-induced forces. Although the currents were intensified along the coast of the Costa da Caparica, a small reduction of velocities can be observed in the northern part of the model domain.

Based on a few existing data in the literature, a uniform granulometry was assumed for the Costa da Caparica model with a diameter of $0.3 \mathrm{~mm}$ (Freire et al., 2006). A more representative set of granulometry data is necessary to better characterise the sediment distribution in the model domain, considering that grain-size sorting is expected to occur due to the complex hydrodynamics, wave variability and bathymet- ric heterogeneities. Thus, the results of sediment transport should be seen as a first qualitative assessment. Moreover, the morphological evolution was ignored at this stage.

The patterns of the bed load sediment transport for the scenarios without waves and under extreme wave conditions are presented in Fig. 15. Along the coast of the Costa da Caparica, the results of the bed load sediment transport are practically null when the wave action was disregarded, suggesting that the tidal currents are irrelevant for the sediment transport in this area. By contrast, simulations including wave forcing show a very strong bed load sediment transport due to waves. However, the importance of the tidal currents for the sediment transport in the inlet of the Tagus Estuary is noticeable. The littoral drift caused by the waves is deflected seaward by the tidal currents during the ebb tide and by the longer groynes present near the estuary inlet.

\section{Conclusions}

The potential of a new modelling approach to simulate the impact of different designs of coastal defence structures was demonstrated in this paper. The coupling between the MOHID modelling system and the SWAN wave model can be useful for engineering studies in order to evaluate the best 
solution to protect the coast against erosion. The speed-up of morphological changes, along with the multiprocessing architecture, allows for the modelling of bed evolution for long periods and for the study of several scenarios. The acceleration factor of 365 allowed us to simulate many years of morphological evolution of a schematic beach with constant wave conditions in a feasible computational time. The bathymetry results reached an equilibrium condition, demonstrating the model stability. The acceleration factor is userdefined, depending on the variability of forcing conditions and speed of morphological changes. The morphological changes should not be speeded up (acceleration factor $=1$ ) to simulate extreme events that occur within few days, as for the case presented for the Costa da Caparica. A more efficient coupling method is currently being developed inside the MOHID code to further reduce the computational time. Moreover, the interface of the MOHID modelling system (MOHID Studio) was developed to make the coupling with SWAN straightforward for all users.

The potential for modelling the evolution of sandbars was also demonstrated in this paper. In the future, an up-to-date methodology can be applied to resolve the vertical variation of wave-induced forces, as well as wave-induced vertical mixing, based on e.g. the generalised Lagrangian mean (GLM) theory implemented in the MOHID code (see Delpey et al., 2014). The test cases shown in this paper are only a preliminary demonstration of model potential, which is thought to be encouraging. The findings of this work confirmed the applicability of the MOHID modelling system in studying sediment transport and morphological changes in coastal systems under the combined action of waves and currents.

The application of the described modelling methodology to a coastal zone located near the inlet of a mesotidal estuary with strong tidal currents allowed for an assessment of the hydrodynamics and sediment transport in situations of calm water conditions (no waves) and under extreme wave conditions. Although these initial results are just a qualitative assessment of sediment transport, the applicability of the modelling methodology to complex cases was demonstrated. In the future, with a more representative set of data, quantitative studies could be performed, taking into account the morphological evolution. Furthermore, the methodology can be used to evaluate different designs of defence structures in order to propose a more efficient solution for the coastline retreat and intense erosion observed in recent years on the coast of the Costa da Caparica.

Data availability. No data sets were used in this article.

Code availability. The MOHID code updated with the developments performed in this work is available in the repository: https: //github.com/Mohid-Water-Modelling-System/Mohid.
Competing interests. The authors declare that they have no conflict of interest.

Acknowledgements. The authors are grateful to the Portuguese Environment Agency (APA) for providing the bathymetry data for the coast of the Costa da Caparica. The first author was financed by the Brazilian National Council for Scientific and Technological Development $(\mathrm{CNPq})$ under the Ciências Sem Fronteiras programme (research grant no. 237448/2012-2). MARETEC acknowledges the ERDF funds of the Competitiveness Factors Operational Programme (COMPETE), and national funds from the Foundation for Science and Technology (FCT) (project UID/EEA/50009/2013).

Edited by: John M. Huthnance

Reviewed by: André B. Fortunato and one anonymous referee

\section{References}

Amoudry, L. O. and Liu, P. L. F.: Parameterization of near-bed processes under collinear wave and current flows from a two-phase sheet flow model, Cont. Shelf Res., 30, 1403-1416, 10.1016/j. csr.2010.04.009, 2010.

Amoudry, L. O. and Souza, A. J.: Impact of sediment-induced stratification and turbulence closures on sediment transport and morphological modelling, Cont. Shelf Res., 31, 912-928, https://doi.org/10.1016/j.csr.2011.02.014, 2011.

Ardhuin, F., Rascle, N., and Belibassakis, K. A.: Explicit wave-averaged primitive equations using a generalized Lagrangian mean, Ocean Model., 20, 35-60, https://doi.org/10.1016/j.ocemod.2007.07.001, 2008.

Blumberg, A. F. and Kantha, L. H.: Open boundary condition for circulation models, J. Hydraul. Eng., 111, 237-255, 1985.

Booij, N., Ris, R., and Holthuijsen, L. H.: A third-generation wave model for coastal regions: 1 . Model description and validation, J. Geophys. Res.-Oceans, 104, 7649-7666, 1999.

Bowen, A. J., Inman, D., and Simmons, V.: Wave "set-down" and set-Up, J. Geophys. Res., 73, 2569-2577, 1968.

Burchard, H., Bolding, K., and Villarreal, M. R.: GOTM, a general ocean turbulence model: theory, implementation and test cases, Space Applications Institute, 1999.

Dally, W. R. and Pope, J.: Detached breakwaters for shore protection, DTIC Document, 1986.

Dean, R. G.: Equilibrium beach profiles: characteristics and applications, J. Coastal Res., 7, 53-84, 1991.

Delpey, M., Ardhuin, F., Otheguy, P., and Jouon, A.: Effects of waves on coastal water dispersion in a small estuarine bay, J. Geophys. Res.-Oceans, 119, 70-86, 2014.

Dolan, T. J. and Dean, R. G.: Multiple longshore sand bars in the upper Chesapeake Bay, Estuar. Coast. Shelf Sci., 21, 727-743, 1985.

Drønen, N. and Deigaard, R.: Quasi-three-dimensional modelling of the morphology of longshore bars, Coast. Eng., 54, 197-215, 2007.

Dubarbier, B., Castelle, B., Marieu, V., and Ruessink, G.: Processbased modeling of cross-shore sandbar behavior, Coast. Eng., 95, 35-50, 2015. 
Einstein, H. A.: The bed-load function for sediment transportation in open channel flows, Citeseer, 1950.

Engedahl, H.: Use of the flow relaxation scheme in a threedimensional baroclinic ocean model with realistic topography, Tellus A, 47, 365-382, 1995.

Flather, R.: A tidal model of the northwest European continental shelf, Mem. Soc. R. Sci. Liege, 10, 141-164, 1976.

Franz, G., Fernandes, R., de Pablo, H., Viegas, C., Pinto, L., Campuzano, F., Ascione, I., Leitão, P., and Neves, R.: Tagus Estuary hydro-biogeochemical model: Inter-annual validation and operational model update. 3.as Jornadas de Engenharia Hidrográfica, Lisbon, Portugal, Extended abstracts, 103-106, 2014a.

Franz, G., Campuzano, F., Fernandes, R., Pinto, L., de Pablo, H., Ascione, I., and Neves, R.: An integrated forecasting system of hydro-biogeochemical and waves in the Tagus estuary, Proceedings of the Seventh EuroGOOS International Conference, Lisbon, 2014b.

Franz, G., Campuzano, F., Pinto, L., Fernandes, R., Sobrinho, J., Simões, A., Juliano, M., and Neves, R.: Implementation and validation of a wave forecasting system for the Portuguese Coast, Proceedings of the Seventh EuroGOOS International Conference, Lisbon, 2014c

Franz, G., Pinto, L., Ascione, I., Mateus, M., Fernandes, R., Leitao, P., and Neves, R.: Modelling of cohesive sediment dynamics in tidal estuarine systems: Case study of Tagus estuary, Portugal, Estuarine, Coast. Shelf Sci., 151, 34-44, 2014d.

Franz, G. A. S., Leitão, P., Santos, A. D., Juliano, M., and Neves, R.: From regional to local scale modelling on the south-eastern Brazilian shelf: case study of Paranaguá estuarine system, Braz. J. Oceanogr., 64, 277-294, 2016.

Franz, G., Leitão, P., Pinto, L., Jauch, E., Fernandes, L., and Neves, R.: Development and validation of a morphological model for multiple sediment classes, Int. J. Sediment Res., https://doi.org/10.1016/j.ijsrc.2017.05.002, in press, 2017.

Freire, P., Taborda, R., and Andrade, C.: Caracterização das praias estuarinas do Tejo, APRH, Congresso da Água, vol. 8, 2006.

Fortunato, A. B., Nahon, A., Dodet, G., Pires, A. R., Freitas, M. C., Bruneau, N., Azevedo, A., Bertin, X., Benevides, P., Andrade, C., and Oliveira, A.: Morphological evolution of an ephemeral tidal inlet from opening to closure: The Albufeira inlet, Portugal, Cont. Shelf Res., 73, 49-63, 2014.

Greenwood, R. and Davis, R. A.: Hydrodynamics and sedimentation in wave-dominated coastal environments, Elsevier, 2011.

Komar, P. D.: Beach Processes and Sedimentation. Upper Saddle River, N.J, Prentice Hall, 1998.

Kriebel, D. L. and Dean, R. G.: Numerical simulation of timedependent beach and dune erosion, Coast. Eng., 9, 221-245, 1985.

Kristensen, S. E., Drønen, N., Deigaard, R., and Fredsoe, J.: Hybrid morphological modelling of shoreline response to a detached breakwater, Coast. Eng., 71, 13-27, 2013.

Leitao, P., Mateus, M., Braunschweig, L., Fernandes, L., and Neves, R.: Modelling coastal systems: the MOHID Water numerical lab, Perspectives on integrated coastal zone management in South America, 77-88, 2008.

Leitão, P. C.: Integração de Escalas e Processos na Modelação do Ambiente Marinho, 2003.

Lemos, P. A. F.: Estuário do Tejo. Administração Geral do Porto de Lisboa, Lisbon, 1972.
Levoy, F., Anthony, E., Monfort, O., and Larsonneur, C.: The morphodynamics of megatidal beaches in Normandy, France, Mar. Geol., 171, 39-59, 2000.

Longuet-Higgins, M. S. and Stewart, R.: Radiation stress and mass transport in gravity waves, with application to "surf beats", J. Fluid Mech., 13, 481-504, 1962.

Longuet-Higgins, M. S. and Stewart, R.: Radiation stresses in water waves; a physical discussion, with applications, Deep Sea Research and Oceanographic Abstracts, Vol. 11, No. 4, Elsevier, 1964.

Longuet-Higgins, M. S.: Longshore currents generated by obliquely incident sea waves: 1, J. Geophys. Res., 75, 6778-6789, 1970a.

Longuet-Higgins, M. S.: Longshore currents generated by obliquely incident sea waves: 2, J. Geophys. Res., 75, 6790-6801, https://doi.org/10.1029/JC075i033p06790, 1970b.

Longuet-Higgins, M. S.: Wave set-up, percolation and undertow in the surf zone, P. Roy. Soc. Lond. A, 390, 283-291, 1983.

Malhadas, M. S., Leitão, P. C., Silva, A., and Neves, R.: Effect of coastal waves on sea level in Óbidos Lagoon, Portugal, Cont. Shelf Res., 29, 1240-1250, 2009.

Malhadas, M. S., Neves, R. J., Leitão, P. C., and Silva, A.: Influence of tide and waves on water renewal in Óbidos Lagoon, Portugal, Ocean Dynam., 60, 41-55, 2010.

Martins, F.: Modelação Matemática Tridimensional de escoamentos costeiros e estuarinos usando uma abordagem de coordenada vertical genérica, $\mathrm{PhD}$ thesis, Universidade Técnica de Lisboa, Instituto Superior Técnico, Lisbon, Portugal, 2000.

Martins, F., Leitão, P. C., Silva, A., and Neves, R.: 3D modelling in the Sado estuary using a new generic vertical discretization approach, Oceanol. Acta, 24, 551-562, 2001.

Martinsen, E. A. and Engedahl, H.: Implementation and testing of a lateral boundary scheme as an open boundary condition in a barotropic ocean model, Coast. Eng., 11, 603-627, 1987.

Myrhaug, D., Holmedal, L. E., and Rue, H.: Bottom friction and bedload sediment transport caused by boundary layer streaming beneath random waves, Appl. Ocean Res., 26, 183-197, 2004.

Nahon, A., Bertin, X., Fortunato, A. B., and Oliveira, A.: Processbased 2DH morphodynamic modeling of tidal inlets: a comparison with empirical classifications and theories, Mar. Geol., 291, $1-11,2012$.

Roelvink, D., Reniers, A., Van Dongeren, A., de Vries, J. v. T., McCall, R., and Lescinski, J.: Modelling storm impacts on beaches, dunes and barrier islands, Coast. Eng., 56, 1133-1152, 2009.

Ruessink, B., Kuriyama, Y., Reniers, A., Roelvink, J., and Walstra, D.: Modeling cross-shore sandbar behavior on the timescale of weeks, J. Geophys. Res.-Earth, 112, F03010, https://doi.org/10.1029/2006JF000730, 2007.

Ruessink, B., Pape, L., and Turner, I.: Daily to interannual crossshore sandbar migration: observations from a multiple sandbar system, Cont. Shelf Res., 29, 1663-1677, 2009.

Saville, T.: Experimental determination of wave set-up, Proceedings of the Second Technical Conference on Hurricanes, Report No. 50, 242-252, 1961.

Smagorinsky, J.: General circulation experiments with the primitive equations: I. The basic experiment, Mon. Weather Rev., 91, 99164, 1963.

Soulsby, R. and Clarke, S.: Bed shear-stresses under combined waves and currents on smooth and rough beds, HR Wallingford, Report TR137, 2005. 
Soulsby, R. L. and Damgaard, J. S.: Bedload sediment transport in coastal waters, Coast. Eng., 52, 673-689, 2005.

Veloso-Gomes, F., Costa, J., Rodrigues, A., Taveira-Pinto, F., PaisBarbosa, J., and Neves, L. D.: Costa da Caparica artificial sand nourishment and coastal dynamics, J. Coast. Res., 1, 678-682, 2009.

Villarreal, M. R., Bolding, K., Burchard, H., and Demirov, E.: Coupling of the GOTM turbulence module to some threedimensional ocean models, in: Marine Turbulence: Theories, Observations and Models, edited by: Baumert, H. Z., Simpson, J. H., and Sündermann, J., Cambridge, Cambridge University Press, 225-237, 2005.
Warner, J. C., Sherwood, C. R., Signell, R. P., Harris, C. K., and Arango, H. G.: Development of a three-dimensional, regional, coupled wave, current, and sediment-transport model, Comput. Geosci., 34, 1284-1306, 2008. 